•研究报告・

\title{
极小种群濒危植物广西火桐、丹霞梧桐的叶绿体基 因组特征
}

陆奇丰 ${ }^{1}$, 黄至欢 ${ }^{2}$, 骆文华 ${ }^{*}$

1. 广西壮族自治区中国科学院广西植物研究所, 广西桂林 541006; 2. 南华大学建筑学院, 湖南衡阳 421001

摘要: 广西火桐(Firmiana kwangsiensis)和丹霞梧桐(F.danxiaensis)是我国南方特有物种, 其分布范围狭窄, 种群数量少。为了 解其叶绿体基因组结构及系统发生关系，本文通过高通量测序方法获得广西火桐和丹霞梧桐的浅层基因组数据，通过生物信 息学方法对叶绿体全基因组进行组装, 并对其结构特征进行分析。结果表明: 广西火桐和丹霞梧桐的叶绿体基因组大小分别 为 160,836 bp 和 $161,253 \mathrm{bp}$, 具有典型被子植物叶绿体基因组环状四分体结构, 包含长度分别为 $89,700 \mathrm{bp} 、 90,142 \mathrm{bp}$ 的大单拷 贝区(large single copy, LSC), 长度分别为 19,970 bp、20,067 bp 的小单拷贝区(small single copy, SSC)及长度分别为25,583 bp、 25,522 bp的2个反向重复序列区(inverted repeat sequence, IR)。两个物种的叶绿体基因组共注释得到131个基因，包括86个蛋白 编码基因、37个tRNA基因和8个rRNA基因。广西火桐的叶绿体基因组中共检测出26个正向重复序列、2个反向重复序列、21 个回文重复序列、21个串联重复序列和 98 个简单重复序列; 丹霞梧桐叶绿体基因组中共检测出23个正向重复序列、5个反向 重复序列、21个回文重复序列、30个串联重复序列和107个简单重复序列。系统发生分析结果表明5种梧桐属(Firmiana)植物 构成两个强烈支持的分支(支持率100\%), 一个分支为广西火桐、美丽火桐(F. pulcherrima)和火桐(F. colorata), 其中广西火桐 与美丽火桐构成姐妹群; 另一分支是互为姐妹群的丹霞梧桐和云南梧桐(F. major)。综上所述, 广西火桐和丹霞梧桐的叶绿体 基因组结构、基因排列及重复序列具有较高的相似性，系统进化树将5种梧桐属物种分为两个分支，其中广西火桐和美丽火桐 最近; 而丹霞梧桐与云南梧桐关系最近。本研究鉴定的SSR位点可为梧桐属物种系统发生、进化关系的研究提供遗传信息。 关键词: 广西火桐; 丹霞梧桐; 叶绿体全基因组; 高通量测序; 重复序列; 系统发生分析

陆奇丰, 黄至欢, 骆文华 (2021) 极小种群濒危植物广西火桐、丹霞梧桐的叶绿体基因组特征. 生物多样性, 29, 586-595. doi: 10.17520/biods.2020263. Lu QF, Huang ZH, Luo WH (2021) Characterization of complete chloroplast genome in Firmiana kwangsiensis and F. danxiaensis with extremely small populations. Biodiversity Science, 29, 586-595. doi: 10.17520/biods.2020263.

\section{Characterization of complete chloroplast genome in Firmiana kwangsiensis and F. danxiaensis with extremely small populations}

Qifeng $\mathrm{Lu}^{1}$, Zhihuan Huang ${ }^{2}$, Wenhua Luo ${ }^{1 *}$

1 Guangxi Institute of Botany, Guangxi Zhuang Autonomous Region and Chinese Academy of Sciences, Guilin, Guangxi 541006

2 School of Architecture, University of South China, Hengyang, Hunan 421001

\section{ABSTRACT}

Aims: Firmiana kwangsiensis and F. danxiaensis are endemic plant species with narrow distribution and small population in southern China, which have important ecological and economic value. However, our knowledge of the chloroplast genome level of $F$. kwangsiensis and $F$. danxiaensis are still limited. Also, the phylogenetic relationships among the Firmiana genus remain unclear.

Methods: The genome skimming sequencing data of $F$. kwangsiensis and $F$. danxiaensis were obtained by using the high-throughput sequencing, and the complete chloroplast genomes were assembled and then the structures were analyzed by bioinformatics methods.

Results: The results revealed that complete chloroplast genomes of the F. kwangsiensis and F. danxiaensis show a

收稿日期: 2020-06-30; 接受日期: 2020-09-10

基金项目：国家自然科学基金(31960083; 31700196)和国家科技基础资源调查专项(2017FY100100)

* 通讯作者 Author for correspondence. E-mail: luowenhua2004@163.com 
typical quadripartite structure of 160,836 bp and161,253 bp in length, consisting of a large single copy region (89,700 bp and 90,142 bp) and a small single copy region (19,970 bp and20,067 bp) that were separated by a pair of inverted repeat regions (25,583 bp and 25,522 bp each). The annotation results showed that chloroplast genomes of both species contain 131 genes, including 86 protein-coding, 37 transfer RNA (tRNA), and eight ribosomal RNA (rRNA) genes. In F. kwangsiensis, 26 forward repeats, two reverse repeats, 21 palindromic repeats, 23 tandem repeats, and 98 simple sequence repeats were found, and 23 forward repeats, five reverse repeats, 21 palindromic repeats, 30 tandem repeats, and 107 simple sequence repeats were found in F. danxiaensis. Phylogenetic analyses revealed that five Firmiana species were clustered into two branches with strong supports. Firmiana kwangsiensis, F. pulcherrima and F. colorata formed a branch, and the F. kwangsiensis was a sister relationship to F. pulcherrima in this branch, the other branch was F. danxiaensis and F. major.

Conclusion: The structures, gene arrangement and repeat sequences in F. kwangsiensis and F. danxiaensis chloroplast genome were high similar. Phylogenetic analyses revealed that five Firmiana species were clustered into two clades, $F$. kwangsiensis was closely related to F. pulcherrima, and F. danxiaensis was closely related to F. major. In addition, the SSRs in this study will provides important genetic information for phylogenetic, evolution for Firmiana species.

Key words: Firmiana kwangsiensis; Firmiana danxiaensis; chloroplast genome; high-throughput sequencing; repeat sequence; phylogenetic analysis

叶绿体是植物细胞内进行光合固碳和胁迫应 答的重要半自主性细胞器(Ivanova et al, 2017), 它 具有一套可独立自主复制的遗传系统, 可编码与光 合作用相关的蛋白。陆生植物中的叶绿体基因组主 要为单亲遗传, 其基因组一般为107-218 kb的环状 DNA分子, 包括1个大单拷贝区(large single copy, LSC)、 1 个小单拷贝区(small single copy, SSC)及被 其分隔开的 2 个反向重复区 (inverted repeat, IR) (Daniell et al, 2016; 李倩等, 2020)。与核基因组相比, 叶绿体基因组具有重组率较低、后代遗传稳定等特 点(Birky, 1995; 于涛等, 2019)。因此, 研究叶绿体基 因组数据有助于揭示物种的系统发生关系。然而, 在以往的研究中, 所选择的核基因组和叶绿体基因 片段较少且获得有效信息偏少, 对物种进化关系的 全面解析产生了一定的影响。随着测序技术的提升 和成本的下降, 利用叶绿体全基因组解析物种系统 发生关系已成为有效的手段。叶绿体基因组信息的 挖掘不仅有助于物种鉴定和分子育种等方面的研 究, 还可为重要经济作物、园艺品种改良、珍稀濒 危植物保育提供分子基础(Nie et al, 2012)。

梧桐属(Firmiana)隶属于锦葵科梧桐亚科, 包 含12-18种(Chen et al, 2015), 中国分布有7种, 分别 为梧桐(F. simplex)、海南梧桐(F. hainanensis)、丹霞 梧桐(F. danxiaensis)、云南梧桐(F. major)、火桐 (F. colorata)、广西火桐(F. kwangsiensis)和美丽火桐 (F. pulcherrima), 其中除梧桐因栽培而分布较广外, 其余6种均为狭域分布种(Wang et al, 2018; Ya et al, 2018; 武星制等, 2018)。随着观赏植物物种需求的
增加，梧桐属部分物种因其优美的树形和鲜艳的花 色而被推广栽培。有研究发现梧桐属植物的提取物 不仅具有抗微生物、抗炎症和抗癌的药理作用 (Ajaib et al, 2014; Woo et al, 2015; Lim et al, 2017), 还具有保护神经系统和护肝的作用(Kim et al, 2015; Lim et al, 2017)。目前, 对梧桐属的系统发生关系已 有相关报道，凡强等(2011)利用ITS片段对梧桐属的 系统发生关系进行了研究; Abdullah等(2019)基于火 桐、云南梧桐和美丽火桐的叶绿体全基因组进行了 系统发生关系分析。为了更准确全面地了解梧桐属 的系统发生关系, 还需要更多物种的相关基因信 息。

广西火桐和丹霞梧桐均为梧桐属内重要的落 叶树种, 其自然分布狭窄, 野外种群数量少, 被列 为国家二级重点保护野生植物(国家林业局和农业 部, 1999)以及《中国物种红色目录》的濒危等级物 种(汪松和解炎, 2004), 并被列入 《全国极小种群野 生植物拯救保护工程规划(2011-2015年)》名录。其 中广西火桐仅分布于广西中部至南部的石灰岩地 区, 丹霞梧桐主要分布于广东丹霞山自然保护区, 是丹霞山特征种及丹霞地貌特有种。这两种植物树 形优美、花色艳丽, 极具园林观赏价值。近年来, 对 这两种植物的相关研究主要集中于资源调查和群 落特征(骆文华等, 2010; 陈璐等, 2018)、群体遗传 分析(Chen et al, 2014; 骆文华等, 2015; 武星粀等, 2018)等方面, 尚未发现利用叶绿体全基因组信息 对广西火桐和丹霞梧桐的系统发生进行研究的相 关报道。因此, 本文以广西火桐和丹霞梧桐的叶片 
为研究材料, 利用高通量测序技术, 对两个物种的 叶绿体全基因组进行组装, 并对其结构特征进行分 析, 希望有助于理解广西火桐和丹霞梧桐的系统发 生关系, 为后续开展其遗传多样性的保护和种群恢 复研究提供分子基础信息。

\section{材料和方法}

\section{1 植物材料及DNA提取}

广西火桐叶片样品于2018年6月采集于桂林植 物园内 $\left(25^{\circ} 04^{\prime} \mathrm{N}, 110^{\circ} 17^{\prime} \mathrm{E}\right)$, 并使用硅胶干燥保 存。丹霞梧桐叶片样品于2019年7月采集于桂林植 物园内幼苗, 该幼苗为2017年7月引种于广东丹霞 山自然保护区 $\left(25^{\circ} 02^{\prime} \mathrm{N}, 113^{\circ} 43^{\prime} \mathrm{E}\right)$, , 叶片样品置 于硅胶内干燥保存。利用改良CTAB法(Doyle, 1987) 提取广西火桐和丹霞梧桐的叶片DNA。随后, 利用 琼脂糖凝胶电泳和NanoDrop2000 (美国赛默飞世尔 科技有限公司)评价基因组DNA的质量及浓度，检 验合格的基因组DNA用于文库构建。

\section{2 叶绿体基因组测序、组装与基因注释}

由于广西火桐与丹霞梧桐采样和测序时间不 一致，并考虑到成本及技术的因素，利用Illumina Hiseq测序平台(上海美吉生物医药科技有限公司) 对广西火桐叶绿体进行浅层基因组测序, 而丹霞梧 桐叶绿体则利用Illumina NovaSeq平台(南京集思慧 远生物科技有限公司)进行浅层基因组测序。两个物 种的建库插入长度均为 $350 \mathrm{bp}$ 左右, 测序读长为 PE150。

为提高叶绿体基因组后续组装及分析的可靠 性，使用fastp软件(Chen et al, 2018)对测序下机后的 原始数据进行过滤, 包括截除reads中的测序接头及 引物序列, 并去除低质量reads (平均质量值 $\mathrm{Q}<5$, 未识别碱基 $\mathrm{N}>5$ )。得到高质量叶绿体基因组测序 数据 (clean data) 后, 用 Bowtie2 v2.2.4 软件 (Langmead et al, 2012)进行比对, 选中比对上的测 序序列作为叶绿体基因组的测序序列。随后, 以瑟 伯氏棉(Gossypium thurberi)叶绿体全基因组(NCBI 登录号：GU907100)为参考序列，通过 SPAdes v3.10.1 (Bankevich et al, 2012)组装广西火桐和丹霞 梧桐的叶绿体全基因组。

为提高叶绿体基因组注释的准确性, 我们通过 以下两种方法对广西火桐和丹霞梧桐的叶绿体基
因组进行注释: (1)使用prodigal v2.6.3 (Hyatt et al, 2010)、 hmmer v3.1b2 (Wu et al, 2011)和aragorn v1.2.38软件(Laslett \& Canbäck, 2004)分别对叶绿体 基因组的蛋白编码区(coding sequences, CDS)、核糖 体RNA (rRNA) 和转运RNA (tRNA)进行注释。(2)提 取参考基因组的基因序列，使用NCBI的blast v2.6 软件比对组装序列, 获得第二种注释结果。然后对 两种注释结果进行对比, 去除错误及冗余的注释, 确定多外显子的边界，从而获得最终的叶绿体基因 注释。利用OGDRAW工具绘制叶绿体基因组结构图 (Lohse et al, 2013)。

\section{3 重复序列与SSR分析}

利用REPuter (Kurtz et al, 2001)软件预测叶绿 体基因组内的散在重复序列，其参数设置为：最小 重复序列为 $30 \mathrm{bp}$, 汉明距离(Hamming distance)设 置为3 (Liang et al, 2019)。串联重复序列通过在线 Tandem Repeats Finder工具进行分析 (Benson, 1999)。利用 MISA软件(Beier et al, 2017)预测叶绿体 基因组的简单重复序列(simple sequence repeats, SSR)的分布, 参数设置如下：大于或等于 10 个单核 苷酸重复序列; 大于或等于5个二核苷酸重复序列; 大于或等于 4 个三核苷酸重复序列; 大于或等于 3 个 四核苷酸及以上核苷酸重复序列(Zhao et al, 2019)。

\section{4 系统发生分析}

从NCBI下载12个锦葵目植物的叶绿体全基因 组序列，包括梧桐属的云南梧桐(NC 037242)、美丽 火桐(NC 036395)、火桐(BK 010724), 银叶树属 (Heritiera)的长柄银叶树(H. angustata, NC 037784)、 H. fomes (NC 043924)、银叶树(H. littoralis, NC 043923)、蝴蝶树 (H. parvifolia, NC 038057), 翅子树 属 (Pterospermum) 的景东翅子树 (P. kingtungense, NC 042885), 椴树属(Tilia)的紫椴(T. amurensis, MH 169579)和少脉椴(T. paucicostata, KT 894775), 棉属 (Gossypium)的G. harknessii (NC 033333)和克劳茨基 棉(G. klotzschianum, NC 033394), 并将本研究中广 西火桐和丹霞梧桐的叶绿体基因组纳入分析，以十 字花科的Braya humilis (NC 035515)为外类群。利用 RAxML (Stamatakis, 2014) 构建最大似然法 (maximum likelihood, ML)的系统发生树, 碱基替换 模型选择GTR+G, 其他参数选择默认设置, 进化树 分支的可信度基于bootstrap抽样重复1,000次。 


\section{结果}

\section{1 叶绿体基因组组装与基本特征}

对测序原始数据的接头序列和低质量测序数 据过滤后，获得广西火桐和丹霞梧桐的clean data分 别约为5.16 G和5.91 G。随后对叶绿体基因组进行 组装, 分别获得了广西火桐和丹霞梧桐的叶绿体全 基因组 (NCBI 登录号分别为 MN786867、 MN480318)。与典型被子植物叶绿体基因组相似, 广西火桐和丹霞梧桐的叶绿体基因组均为闭合环 状四分体结构，包含LSC、SSC及两个IR区(图1)，序 列全长分别为160,836 bp和161,253 bp, 其中LSC区 长度分别为89,700 bp和90,142 bp, SSC区长度分别 为19,970 bp和20,067 bp, IR区长度分别为 $25,583 \mathrm{bp}$ 和25,522 bp。广西火桐与丹霞梧桐的叶绿体基因组 GC含量分别为 $37.04 \% 、 36.87 \%$, 且两者的IR区GC 含量(42.93\%、42.97\%)均高于LSC (34.92\%、34.68\%) 和SSC区(31.46\%、31.24\%) (表1)。

本研究中, 广西火桐与丹霞梧桐的叶绿体基因 组注释到的基因总数均为 131 个, 包括 86 个蛋白编 码序列、37个tRNA基因和 8 个rRNA基因。其中有 17 个基因存在两个拷贝，包括6个蛋白编码序列(rps7、

表1 广西火桐和丹霞梧桐的叶绿体基因组特征比较

Table 1 Comparison of chloroplast genome characteristics of Firmiana kwangsiensis and F. danxiaensis

\begin{tabular}{lll}
\hline 基因组特征 & 广西火桐 & 丹霞梧桐 \\
Genome characteristics & F. kwangsiensis & F. danxiaensis \\
\hline 序列全长 Genome size (bp) & 160,836 & 161,253 \\
LSC区长度 LSC length (bp) & 89,700 & 90,142 \\
SSC区长度 SSC length (bp) & 19,970 & 20,067 \\
IR区长度 IR length (bp) & 25,583 & 25,522 \\
GC含量 GC content (\%) & 37.04 & 36.87 \\
LSC区GC含量 GC content of LSC & 34.92 & 34.68 \\
(\%) & & \\
SSC区GC含量 GC content of SSC & 31.46 & 31.24 \\
(\%) & & 42.97 \\
IR区GC含量 GC content of IR (\%) & 42.93 & 31.13 \\
A碱基占比 A base content (\%) & 30.98 & 31.99 \\
T碱基占比 T base content (\%) & 31.98 & 18.61 \\
C碱基占比 C base content (\%) & 18.87 & 18.26 \\
G碱基占比 G base content (\%) & 18.17 \\
基因总数 Total genes & 131 & 131 \\
编码蛋白基因数 No. of protein & 86 & 86 \\
coding sequences & 37 & 37 \\
tRNA & 8 & 8 \\
rRNA & & \\
\hline
\end{tabular}

$r p l 2 、 r p l 23 、 n d h B 、 y c f 2 、 y c f 15) 、 7$ 个 tRNA 基因 (trnA-UGC 、 trnI-CAU 、 trnI-GAU 、 trnL-CAA 、 $\operatorname{trn} N-G U U$ 、trnR-ACG、trnV-GAC)和 4 个 rRNA 基 因( rrn16、rrn23、rrn4.5、rrn5) (附录 1)。在广西火 桐和丹霞梧桐的叶绿体基因组中均发现 17 个基因 含有内含子, 其中 14 个基因含有 1 个内含子，包括 8 个蛋白编码基因( $r p s 16 、 a t p F 、 r p o C 1 、 p e t B 、 p e t D 、$ $r p l 2 、 n d h B 、 n d h A)$ 和 6 个 tRNA 基因(trnK-UUU、 trnG-UCC 、 trnL-UAA 、 trnV-UAC 、 trnI-GAU 、 $\operatorname{trn} A-U G C)$; 有 3 个基因含有 2 个内含子(rps12、 $y c f 3 、 c l p P)$ 。 matK 基因位于 $t r n K-U U U$ 的内含子上。 另外, rps12 为反式剪接基因, 其 5’端位于 LSC 区, 而3'端位于 IR 区。

\subsection{SSR分析}

利用MISA软件对广西火桐的叶绿体基因组篮 选得到 98 个SSR位点, 包括56个单核苷酸重复类型 (主要以 $A$ 或 $T$ 碱基重复为主, 只有 3 个为 $C$ 碱基重复), 7 个双核苷酸、 2 个三核苷酸、11 个四核苷酸、5 个 五核苷酸和 17 个复合核苷酸类型; 而在丹霞梧桐叶 绿体基 因组笁选得到107个SSR位点, 其中64个为 A或 T组成的单核苷酸重复类型，11个双核苷酸、1 个三核苷酸、9个四核苷酸、9个五核苷酸和13个复 合核苷酸类型(图2A)。广西火桐和丹霞梧桐的叶绿 体基因组SSR位点主要分布于LSC区(分别为70和 82 个), 其次为 SSC区 (分别为 18 和 15 个), IR区最少 (各10个) (图2B); 另外, SSR位点大部分分布于叶绿 体基因组的非编码区上，且基因间隔区(IGS)分布 最多(分别有65和74个), 其次为基因内含子区(19和 17个), 而在基因编码区分布较少(14和16个) (图2C, 附录2)。

\section{3 重复序列分析}

利用REPuter软件对广西火桐和丹霞梧桐的叶 绿体基因组进行重复序列分析。在广西火桐的叶绿 体基因组共鉴定出 49 个重复序列，包括26个正向重 复(forward repeats)、2 个反向重复(reverse repeats)和 21 个回文重复(palindromic repeats); 在丹霞梧桐的 基因组中也鉴定出 49 个散在重复序列，包括23个正 向重复、5个反向重复和 21 个回文重复(图3A)。广西 火桐和丹霞梧桐叶绿体基因组重复序列长度范围 分别在30-65 bp和30-60 bp之间, 且主要分布于 30-45 bp之间(图3C, 附录3)。在两个物种的ycf2、 $p s a B$ 和 $y c f 1$ 编码区上均有重复序列的分布, 且 $y c f 2$ 


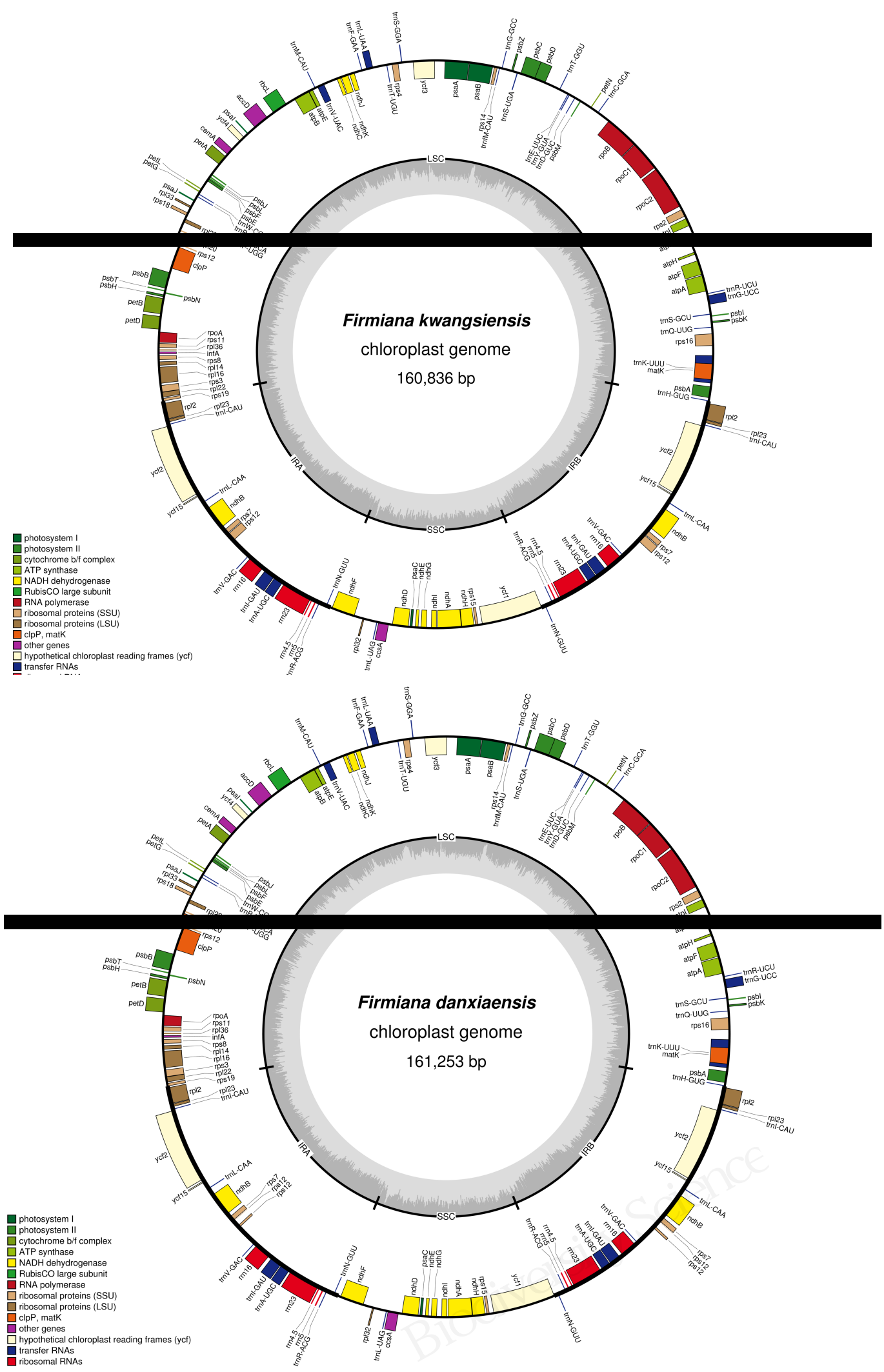

图1 广西火桐和丹霞梧桐叶绿体基因组的基因图谱

Fig. 1 Gene map of the Firmiana kwangsiensis and F. danxiaensis chloroplast genome 

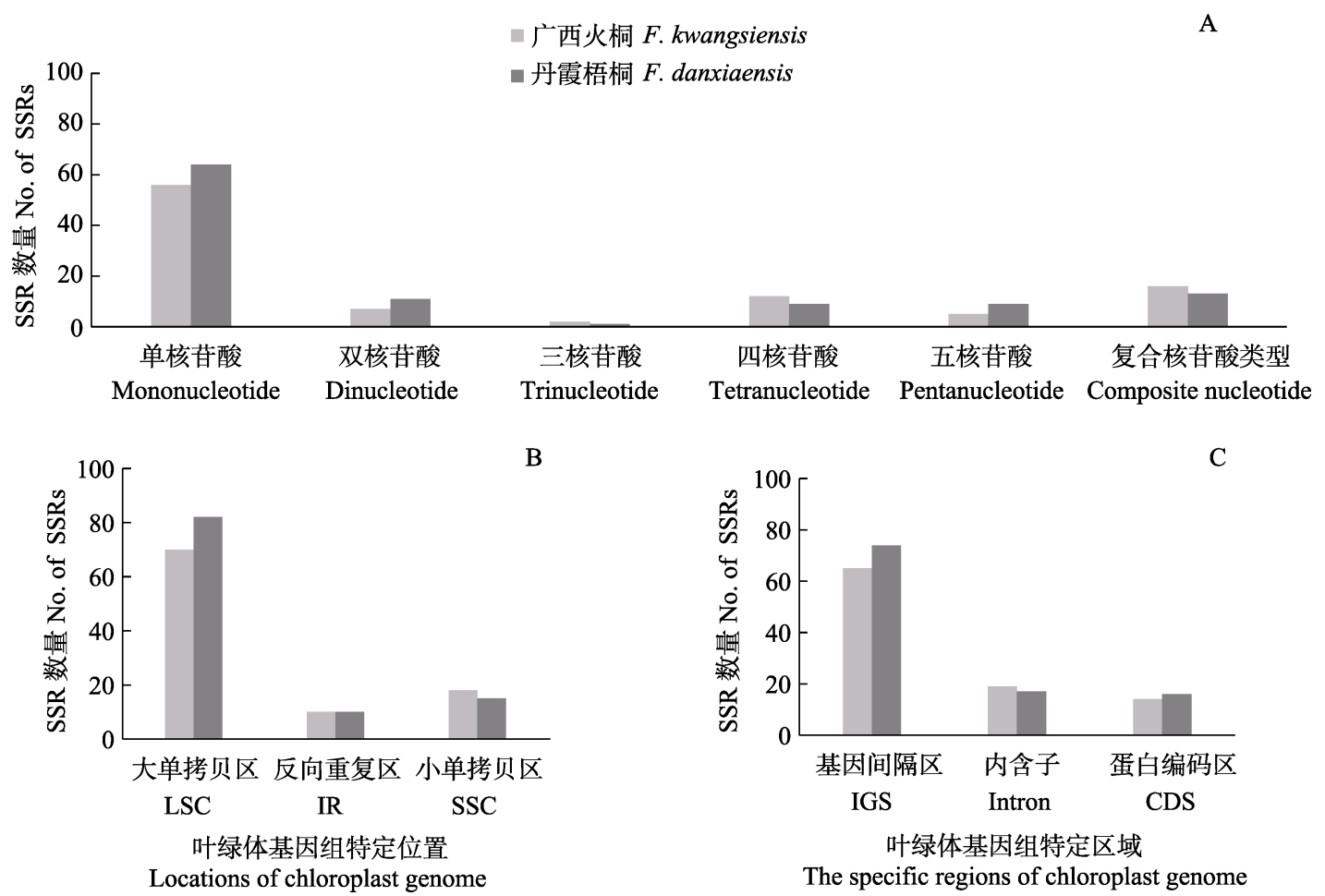

图2 广西火桐和丹霞梧桐的叶绿体基因组SSR分析。(A)不同SSR类型的数量; (B)大单拷贝区 $(L S C)$; 反向重复区 $(I R)$ 和小单 拷贝区(SSC)的SSR数量; (C)基因间隔区(IGS)、基因编码区(CDS)及内含子(intron)的SSR数量。

Fig. 2 SSR analysis of the chloroplast genomes of Firmiana kwangsiensis and F. danxiaensis. (A) Number of SSRs in different types; (B) Number of SSRs in the LSC (large single copy), SSC (small single copy), and IR (inverted repeat region); (C) Number of SSRs in the intergenic regions (IGS), protein-coding gene (CDS) and introns.
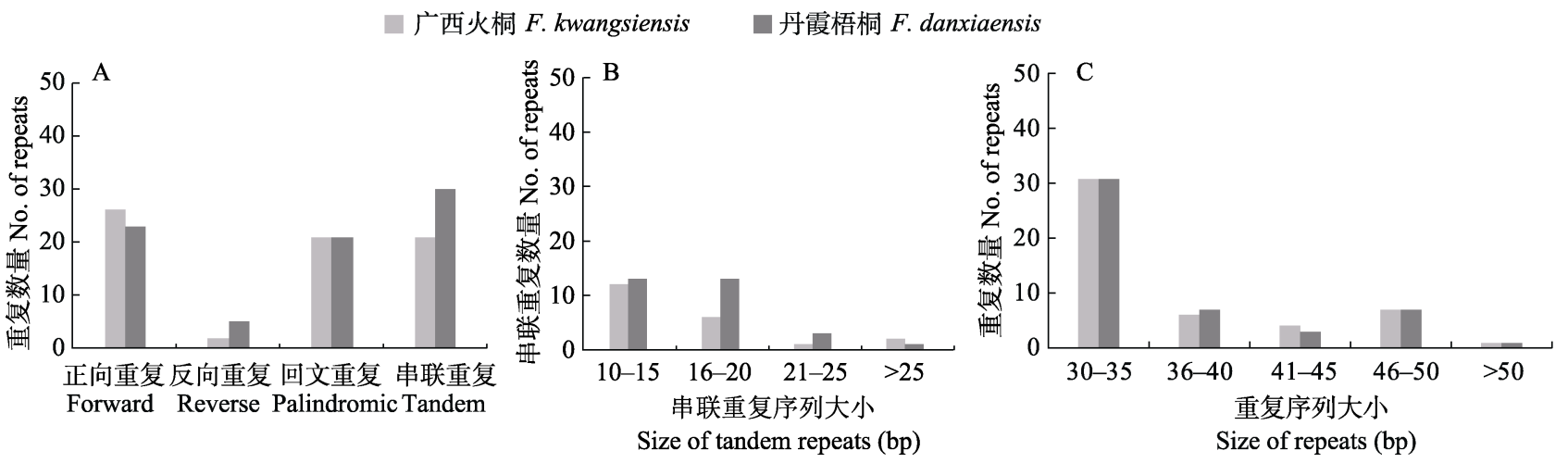

图3 广西火桐和丹霞梧桐的叶绿体基因组重复序列分析。(A)不同重复序列类型的分布数量; (B)串联重复序列长度的分布范 围; (C)正向、反向和回文重复序列长度的分布范围。

Fig. 3 Repeat sequences analysis of Firmiana kwangsiensis and F. danxiaensis chloroplast genome. (A) Number of different types of repeats; (B) Size of tandem repeats in specific range; (C) Size of forward, reverse and palindromic repeats in specific range.

编码区分布数量最多(均有17个); $t R N A-G C U$ 基因上 各分布有 1 个重复序列; 在 $y c f 3 、 \operatorname{clpP}$ 和 $n d h A$ 的内含 子上也发现有重复序列分布。此外, 在丹霞梧桐的 叶绿体rrn4.5基因上发现有 4 个重复序列, 而广西火 桐的rRNA基因则无重复序列(附录3)。

通过Tandem Repeats Finder软件(https://tandem. bu.edu/)鉴定出广西火桐和丹霞梧桐的叶绿体基因 组的串联重复序列分别有 21 个和 30 个(图3A), 长度 在10-32 bp之间(图3B，附录4)。这些串联重复序列 的重复次数基本为 2 次，但在丹霞梧桐叶绿体基因 组发现1个重复次数为3的串联重复序列。两个物种 的叶绿体基因组均有 3 个串联重复序列分布于 $c l p P$ 


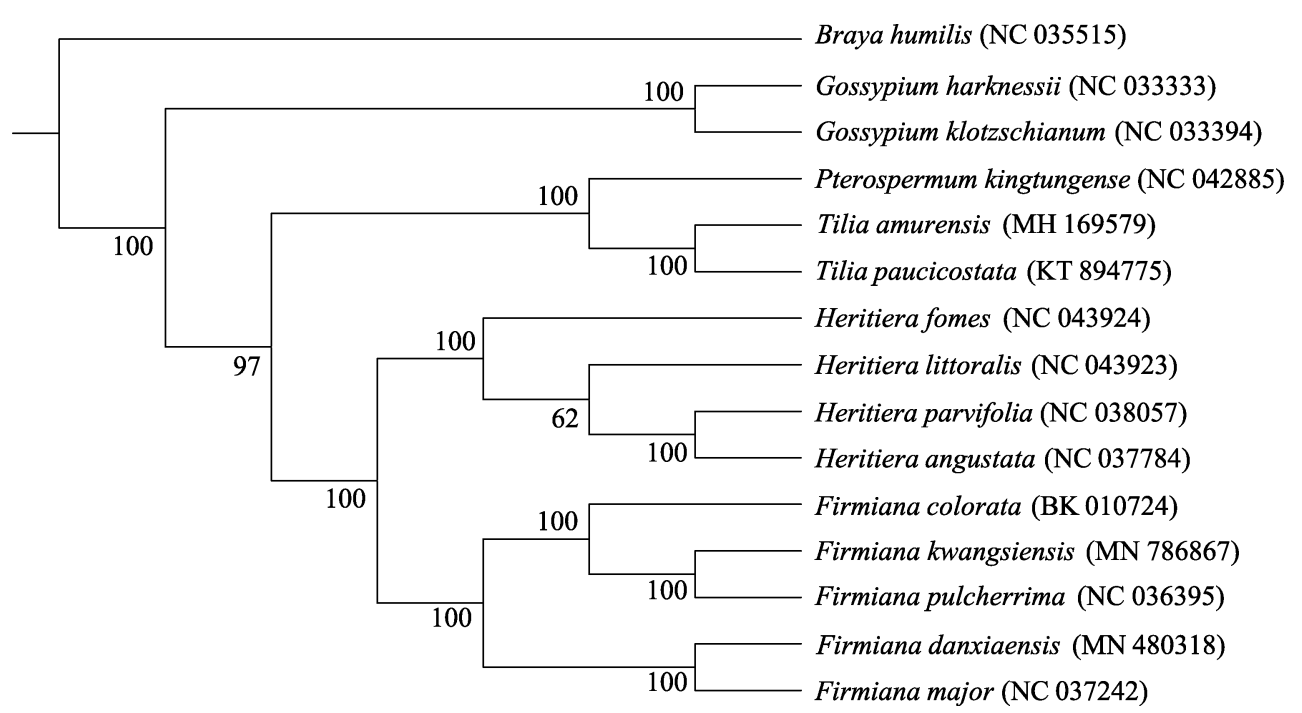

图4 基于叶绿体全基因组序列最大似然法构建的15个物种的系统发生树

Fig. 4 Phylogenetic tree of 15 species based on chloroplast genome using maximum likelihood (ML) method

和 $r p l 2$ 的内含子上，其余均分布于基因间隔区(IGS) (附录4)。

\section{4 系统发生分析}

基于15个物种的叶绿体全基因组序列构建的 系统树显示(图 4): 棉属(Gossypium)、银叶树属 (Heritiera)、梧桐属(Firmiana)和椴树属(Tilia)的单系 性得到强烈支持(支持率均为 $100 \%$ ), 景东翅子树 $(P$. kingtungense)与椴树属形成姐妹群, 并得到100\%支 持, 共同构成银叶树属和梧桐属分支的姐妹群, 支 持率为 $97 \%$ 。在梧桐属内部, 丹霞梧桐和云南梧桐 构成一支, 其余3种(广西火桐、美丽火桐和火桐)构 成一支, 其中广西火桐和美丽火桐为姐妹群关系。

\section{3 讨论}

本研究利用二代高通量测序技术对梧桐属内 濒危极小种群植物广西火桐和丹霞梧桐的叶绿体 全基因组进行组装与注释。两个物种叶绿体基因组 与大多数被子植物的叶绿体基因组结构相似, 均为 典型的四分体式结构(Cheng et al, 2020; Tan et al, 2020), 其长度分别为 160,836 和 $161,253 \mathrm{bp}$ 。二者的 叶绿体基因组均编码 131 个基因, 包括 86 个蛋白编 码序列, 37个tRNA和 8 个rRNA基因。此外, 广西火 桐和丹霞梧桐的叶绿体基因组结构、基因数量和类 型、GC含量等与已公布的梧桐属植物(Ya et al, 2018)、美丽火桐(Wang et al, 2018)和火桐(Abdullah et al, 2019)的叶绿体基因组相似, 表明梧桐属内相
关物种的叶绿体基因组结构相对保守。

有研究发现叶绿体基因组的重排决定了重复 序列的数量(Haberle et al, 2008; Gao et al, 2009; Somaratne et al, 2019)。因此, 重复序列为基因组重 排的研究提供了有效信息。本研究中, 虽然在广西 火桐和丹霞梧桐的叶绿体基因组中均鉴定出 49 个 重复序列, 但在正向重复和反向重复的数量上有一 定的差异, 在其他梧桐属植物如云南梧桐、美丽火 桐和火桐也发现类似现象(Abdullah et al, 2019)。这 些重复序列为梧桐属系统进化的进一步深入研究 提供了重要依据。此外, 我们还发现串联重复序列 的数量及长度在两个物种中也存在差异, 丹霞梧桐 叶绿体基因组大于 $15 \mathrm{bp}$ 以上的串联重复序列数量 要多于广西火桐, 目前关于串联重复序列的起源机 制尚不清楚，可能与DNA重排、变异和基因复制相 关(Chen et al, 2019)。

叶绿体基因组的SSRs是一种被应用于群体遗 传结构和谱系地理学等研究的高效标记工具(Du et al, 2012; Chmielewski et al, 2015)。本研究中, 在广 西火桐和丹霞梧桐的叶绿体基因组中分别获得 98 个和107个SSR位点, 这些SSR位点可以为濒危梧桐 属植物的遗传多样性和保护遗传学等研究提供候 选分子标记。与大多数被子植物的叶绿体基因组 SSR位点分布相似(Abdullah et al, 2019; 乔永刚等, 2019; 张明英等, 2020), 本文两个物种的叶绿体基 因组SSR位点主要分布于LSC区, 且主要以 $A / T$ 碱 
基组成。此外, 非编码区(IGS和内含子)的SSR位点 出现的数量远多于编码区(CDS), 这可能与编码区 的保守性高于非编码区有关(乔永刚等, 2019)。

植物叶绿体基因组序列(如matK、psbA-trnH、 $\operatorname{trnL}$-trnF、ndhF和ycf1等)常被用于物种的系统发生 关系研究(蒋明等, 2020)。但对于梧桐亚科等一些复 杂类群, 有限的DNA片段信息并不能充分揭示其系 统发生关系(Wilkie et al, 2006), 需要更多的分子信 息。本研究基于叶绿体全基因组构建系统发生关系, 将 14 个锦葵科物种明确划分为 5 个分支 (支持率 100\%), 其中锦葵科棉属与梧桐亚科构成姐妹群; 梧桐亚科的梧桐属与银叶树属互为姐妹群, 表明这 两个属的亲缘关系较近, 印证了Wilkie等(2006)的 结论。此外, 梧桐属内部分为两个分支, 其中广西 火桐、火桐和美丽火桐聚为一支, 丹霞梧桐和云南 梧桐构成一支，与凡强等(2011)基于ITS片段的梧桐 属内系统发育关系研究结论一致。但目前受限于梧 桐亚科内其他物种的叶绿体基因组尚未测序公布, 尚未能整体重构其系统发生关系。本研究报道的广 西火桐和丹霞梧桐的叶绿体基因组特征为梧桐属 乃至梧桐亚科物种系统发生、进化和保护遗传学等 研究提供了重要的遗传信息。

\section{参考文献}

Abdullah, Shahzadi I, Mehmood F, Ali Z, Malik MS, Waseem S, Mirza B, Ahmed I, Waheed MT (2019) Comparative analyses of chloroplast genomes among three Firmiana species: Identification of mutational hotspots and phylogenetic relationship with other species of Malvaceae. Plant Gene, 19, 100199.

Ajaib M, Wahla SQ, Khan KM (2014) Firmiana simplex: A potential source of antimicrobials. Journal of the Chemical Society of Pakistan, 36, 744-753.

Bankevich A, Nurk S, Antipov D, Gurevich AA, Dvorkin M, Kulikov AS, Lesin VM, Nikolenko SI, Pham S, Prjibelski AD, Pyshkin AV, Sirotkin AV, Vyahhi N, Tesler G, Alekseyev MA, Pevzner PA (2012) SPAdes: A new genome assembly algorithm and its applications to single-cell sequencing. Journal of Computational Biology, 19, 455-477.

Beier S, Thiel T, Münch T, Scholz U, Mascher M (2017) MISA-web: A web server for microsatellite prediction. Bioinformatics, 33, 2583-2585.

Benson G (1999) Tandem repeats finder: A program to analyze DNA sequences. Nucleic Acids Research, 27, 573-580.

Birky CW (1995) Uniparental inheritance of mitochondrial and chloroplast genes: Mechanisms and evolution. Proceedings of the National Academy of Sciences, USA, 92, 11331-11338.

Chen L, Zhou H, Wang MQ, Wu XT, Lin XY, Zhang Y, Wen YF (2018) Community characteristics comparison of Firmiana danxiaensis species. Chinese Wild Plant Resources, 37(2), 46-49. (in Chinese with English abstract) [陈璐, 周宏, 王敏求, 武星粀, 林雪䒯, 张原, 文亚峰 (2018) 丹霞梧桐群落特征比较研究. 中国野生植物资源, 37(2), 46-49.]

Chen Q, Wu XB, Zhang DQ (2019) Phylogenetic analysis of Fritillaria cirrhosa D. Don and its closely related species based on complete chloroplast genomes. PeerJ, 7, e7480.

Chen SF, Li MW, Hou RF, Liao WB, Zhou RC, Fan Q (2014) Low genetic diversity and weak population differentiation in Firmiana danxiaensis, a tree species endemic to Danxia landform in northern Guangdong, China. Biochemical Systematics and Ecology, 55, 66-72.

Chen SF, Zhou YQ, Chen YR, Gu J (2018) Fastp: An ultra-fast all-in-one FASTQ preprocessor. Bioinformatics, 34, i884-i890.

Chen SF, Li MW, Jing HJ, Zhou RC, Yang GL, Wu W, Fan Q, Liao WB (2015) De novo transcriptome assembly in Firmiana danxiaensis, a tree species endemic to the Danxia landform. PLoS ONE, 10, e0139373.

Cheng Y, Zhang LM, Qi JM, Zhang LW (2020) Complete chloroplast genome sequence of Hibiscus cannabinus and comparative analysis of the Malvaceae family. Frontiers in Genetics, 11, 227.

Chmielewski M, Meyza K, Chybicki IJ, Dzialuk A, Litkowiec M, Burczyk J (2015) Chloroplast microsatellites as a tool for phylogeographic studies: The case of white oaks in Poland. iForest, 8, 765-771.

Daniell H, Lin CS, Yu M, Chang WJ (2016) Chloroplast genomes: Diversity, evolution, and applications in genetic engineering. Genome Biology, 17, 134.

Doyle JJ (1987) A rapid DNA isolation procedure for small quantities of fresh leaf tissue. Phytochemical Bulletin, 19, 11-15.

Du QZ, Wang BW, Wei ZZ, Zhang DQ, Li BL (2012) Genetic diversity and population structure of Chinese white poplar (Populus tomentosa) revealed by SSR markers. Journal of Heredity, 103, 853-862.

Fan Q, Guo W, Chen SF, Liao WB (2011) Phylogeny of Firmiana (Sterculiaceae) based on nrDNA ITS analysis. In: The 10th Youth Academic Seminar of National System and Evolutionary Botany (ed. Botanic Society of Yunnan), p. 68. Kunming. (in Chinese with English abstract) [凡强, 郭微, 陈素芳, 廖文波 (2011) 基于nrDNA ITS序列探讨梧桐属 的系统发育. 见: 2011年全国系统与进化植物学暨第十届 青年学术研讨会论文集(云南植物学会编), 68页. 昆明.]

Gao L, Yi X, Yang YX, Su YJ, Wang T (2009) Complete chloroplast genome sequence of a tree fern Alsophila 
spinulosa: Insights into evolutionary changes in fern chloroplast genomes. BMC Evolutionary Biology, 9, 130.

Haberle RC, Fourcade HM, Boore JL, Jansen RK (2008) Extensive rearrangements in the chloroplast genome of Trachelium caeruleum are associated with repeats and tRNA genes. Journal of Molecular Evolution, 66, 350-361.

Hyatt D, Chen GL, Locascio PF, Land ML, Larimer FW, Hauser LJ (2010) Prodigal: Prokaryotic gene recognition and translation initiation site identification. BMC Bioinformatics, 11, 119.

Ivanova Z, Sablok G, Daskalova E, Zahmanova G, Apostolova E, Yahubyan G, Baev V (2017) Chloroplast genome analysis of resurrection tertiary relict Haberlea rhodopensis highlights genes important for desiccation stress response. Frontiers in Plant Science, 8, 204.

Jiang M, Wang JF, Ying MH, Yang RM, Ma JY (2020) Assembly and sequence analysis of Tetrastigma hemsleyanum chloroplast genome. Chinese Traditional and Herbal Drugs, 51, 461-468. (in Chinese with English abstract) [蒋明, 王军峰, 应梦豪, 杨如棉, 马佳莹 (2020) 三叶崖爬藤叶绿体基因组的组装与序列分析. 中草药, 51, 461-468.]

Kim JW, Yang H, Cho N, Kim B, Kim YC, Sung SH (2015) Hepatoprotective constituents of Firmiana simplex stem bark against ethanol insult to primary rat hepatocytes. Pharmacognosy Magazine, 11(41), 55-60.

Kurtz S, Choudhuri JV, Ohlebusch E, Schleiermacher C, Stoye J, Giegerich R (2001) REPuter: The manifold applications of repeat analysis on a genomic scale. Nucleic Acids Research, 29, 4633-4642.

Langmead B, Salzberg SL (2012) Fast gapped-read alignment with Bowtie 2. Nature Methods, 9, 357-359.

Laslett D, Canback B (2004) ARAGORN, a program to detect tRNA genes and tmRNA genes in nucleotide sequences. Nucleic Acids Research, 32, 11-16.

Li Q, Guo QQ, Gao C, Li HE (2020) Characterization of complete chloroplast genome of Camellia weiningensis in Weining, Guizhou Province. Acta Horticulturae Sinica, 47, 779-787. (in Chinese with English abstract) [李倩, 郭其强, 高超, 李慧娥 (2020) 贵州威宁红花油茶的叶绿体基因 组特征分析. 园艺学报, 47, 779-787.]

Liang CL, Wang L, Lei J, Duan BZ, Ma WS, Xiao SM, Qi HJ, Wang Z, Liu YQ, Shen XF, Guo S, Hu HY, Xu J, Chen SL (2019) A comparative analysis of the chloroplast genomes of four Salvia medicinal plants. Engineering, 5, 907-915.

Lim SY, Subedi L, Shin D, Kim CS, Lee KR, Kim SY (2017) A new neolignan derivative, balanophonin isolated from Firmiana simplex delays the progress of neuronal cell death by inhibiting microglial activation. Biomolecules \& Therapeutics, 25, 519-527.

Luo WH, Mao SZ, Ding L, Huang YS, Deng T (2010) Study on community characteristics of endangered species Erythropsis kwangsiensis. Journal of Fujian Forestry Science and
Technology, 37(4), 6-10. (in Chinese with English abstract) [骆文华, 毛世忠, 丁莉, 黄俞淞, 邓涛 (2010) 濒危植物 广西火桐群落特征研究. 福建林业科技, 37(4), 6-10.]

Luo WH, Dai WJ, Liu J, Hu XH, Li XJ, Huang SX (2015) Comparison of genetic diversity of natural and ex-situ conservation populations of Erythropsis kwangsiensis. Journal of Central South University of Forestry \& Technology, 35(2), 66-71. (in Chinese with English abstract) [骆文华, 代文娟, 刘建, 胡兴华, 李祥军, 黄仕 训 (2015) 广西火桐自然种群和迁地保护种群的遗传多 样性比较. 中南林业科技大学学报, 35(2), 66-71.]

Lohse M, Drechsel O, Kahlau S, Bock R (2013) OrganellarGenomeDRAW-A suite of tools for generating physical maps of plastid and mitochondrial genomes and visualizing expression data sets. Nucleic Acids Research, 41, W575-W581.

National Forestry Administration, Ministry of Agriculture (1999) List of Key State Protected Wild Plants (The first bacth). Plant Journal, (5), 4-11. [国家林业局, 农业部 (1999) 国家重点保护野生植物名录(第一批). 植物杂志, (5), 4-11.]

Nie XJ, Lü SZ, Zhang YX, Du XH, Wang L, Biradar SS, Tan XF, Wan FH, Song WN (2012) Complete chloroplast genome sequence of a major invasive species, crofton weed (Ageratina adenophora). PLoS ONE, 7, e36869.

Qiao YG, He JX, Wang YF, Cao YP, Jia MJ, Zhang XR, Liang JP, Song Y (2019) Analysis of chloroplast genome and its characteristics of medicinal plant Sophora flavescens. Acta Pharmaceutica Sinica, 54, 2106-2112. (in Chinese with English abstract) [乔永刚, 贺嘉欣, 王勇飞, 曹亚萍, 贾孟 君, 张金瑞, 梁建萍, 宋芸 (2019) 药用植物苦参的叶绿 体基因组及其特征分析. 药学学报, 54, 2106-2112.]

Somaratne Y, Guan DL, Wang WQ, Zhao L, Xu SQ (2019) Complete chloroplast genome sequence of Xanthium sibiricum provides useful DNA barcodes for future species identification and phylogeny. Plant Systematics and Evolution, 305, 949-960.

Stamatakis A (2014) RAxML version 8: A tool for phylogenetic analysis and post-analysis of large phylogenies. Bioinformatics, 30, 1312-1313.

Tan W, Gao H, Zhang HY, Yu XL, Tian XX, Jiang WL, Zhou K (2020) The complete chloroplast genome of Chinese medicine (Psoralea corylifolia): Molecular structures, barcoding and phylogenetic analysis. Plant Gene, 21, 100216.

Wang JH, Cai YC, Zhao KK, Zhu ZX, Zhou RC, Wang HF (2018) Characterization of the complete chloroplast genome sequence of Firmiana pulcherrima (Malvaceae). Conservation Genetics Resources, 10, 445-448.

Wang S, Xie Y (2004) China Species Red List (Vol. 1). Higher Education Press, Beijing. (in Chinese) [汪松, 解炎 (2004) 中国物种红色名录(第一卷). 高等教育出版社, 北京.]

Wilkie P, Clark A, Pennington RT, Cheek M, Bayer C, Wilcock CC (2006) Phylogenetic relationships within the 
subfamily Sterculioideae (Malvaceae/Sterculiaceae-Sterculieae) using the chloroplast gene $n d h F$. Systematic Botany, 31, 160-170.

Woo KW, Choi SU, Kim KH, Lee KR (2015) Ursane saponins from the stems of Firmiana simplex and their cytotoxic activity. Journal of the Brazilian Chemical Society, 26, 1450-1456.

Wu ST, Zhu ZW, Fu LM, Niu BF, Li WZ (2011) WebMGA: A customizable web server for fast metagenomic sequence analysis. BMC Genomics, 12, 444.

Wu XT, Chen L, Wang MQ, Zhang Y, Lin XY, Li XY, Zhou $\mathrm{H}$, Wen YF (2018) Population structure and genetic divergence in Firmiana danxiaensis. Biodiversity Science, 26, 1168-1179. (in Chinese with English abstract) [武星粀, 陈璐, 王敏求, 张原, 林雪荣, 李舎金玉, 周宏, 文亚峰 (2018) 丹霞梧桐群体遗传结构及其遗传分化. 生物多样 性, 26, 1168-1179.]

Ya JD, Yu ZX, Yang YQ, Zhang SD, Zhang ZR, Cai J, Yang JB, Yu WB (2018) Complete chloroplast genome of Firmiana major (Malvaceae), a critically endangered species endemic to southwest China. Conservation Genetics
Resources, 10, 713-715.

Yu T, Zhang YY, Gao J, Ke L, Ma WB, Li JQ (2019) Complete chloroplast genome sequence of Betula halophila, a plant species with extremely small populations. Scientia Silvae Sinicae, 55(2), 41-49. (in Chinese with English abstract) [于涛, 张宇阳, 高健, 柯蕾, 马文宝, 李俊清 (2019) 极小种群濒危植物盐桦叶绿体基因组特征分析. 林业科学, 55(2), 41-49.]

Zhang MY, Wang XF, Gao J, Liu AP, Yan YG, Yang XJ, Zhang G (2020) Complete chloroplast genome of Paeonia mairei H. Lév.: Characterization and phylogeny. Acta Pharmaceutica Sinica, 55, 168-176. (in Chinese with English abstract) [张明英, 王西芳, 高静, 刘阿萍, 颜永 刚, 杨新杰, 张岗 (2020) 美丽药药叶绿体全基因组解析 及系统发育分析. 药学学报, 55, 168-176.]

Zhao XQ, Yan M, Ding Y, Huo Y, Yuan ZH (2019) Characterization and comparative analysis of the complete chloroplast genome sequence from Prunus avium 'Summit'. PeerJ, 7, e8210.

(责任编委: 葛学军 责任编辑: 时意专)

\section{附录 Supplementary Material}

附录1 广西火桐和丹霞梧桐的叶绿体基因组注释基因

Appendix 1 List of the annotated genes in chloroplast genome of Firmiana kwangsiensis and F. danxiaensis https://www.biodiversity-science.net/fileup/PDF/2020263-1.pdf

\section{附录2 广西火桐和丹霞梧桐的叶绿体基因组SSR位点信息}

Appendix 2 SSR sequences identified in Firmiana kwangsiensis and F. danxiaensis chloroplast genome https://www.biodiversity-science.net/fileup/PDF/2020263-2.pdf

\section{附录3 广西火桐和丹霞梧桐的叶绿体基因组重复序列}

Appendix 3 The repeat sequences identified in Firmiana kwangsiensis and F. danxiaensis chloroplast genome https://www.biodiversity-science.net/fileup/PDF/2020263-3.pdf

\section{附录4 广西火桐和丹霞梧桐的串联重复序列}

Appendix 4 The tandem repeat sequences identified in Firmiana kwangsiensis and F. danxiaensis chloroplast genome https://www.biodiversity-science.net/fileup/PDF/2020263-4.pdf 
陆奇丰, 黄至欢, 骆文华 (2021) 极小种群濒危植物广西火桐、丹霞梧桐的叶绿体基因组特征. 生物多样性, 29(5), 586-595. http://www.biodiversity-science.net/CN/10.17520/biods.2020263

\section{附录 1 广西火桐和丹霞梧桐的叶绿体基因组注释基因}

Appendix 1 List of the annotated genes in chloroplast genome of Firmiana kwangsiensis and F. danxiaensis

\begin{tabular}{|c|c|c|}
\hline $\begin{array}{l}\text { 基因分类 } \\
\text { Category }\end{array}$ & 基因分组 Group of gene & 基因名称 Name of genes \\
\hline \multirow{5}{*}{$\begin{array}{l}\text { 表达相关基因 } \\
\text { Self- } \\
\text { replication }\end{array}$} & 核糖体 RNA 基因 & \multirow[t]{2}{*}{$r r n 16(\times 2), r r n 23(\times 2), r r n 4.5(\times 2), r r n 5(\times 2)$} \\
\hline & Ribosomal RNAs & \\
\hline & $\begin{array}{l}\text { 转运 RNA 基因 Transfer } \\
\text { RNAs }\end{array}$ & $\begin{array}{l}\operatorname{trn} A-U G C(\times 2), \operatorname{trn} C-G C A, \operatorname{trn} D-G U C, \operatorname{trn} E-U U C, \operatorname{trn} F-G A A, \operatorname{trn} f M-C A U, \\
\operatorname{trn} G-G C C, \operatorname{trn} G-U C C, \operatorname{trn} H-G U G, \operatorname{trn} I-C A U(\times 2), \operatorname{trn} I-G A U(\times 2), \operatorname{trn} K- \\
U U U, \operatorname{trn} L-C A A(\times 2), \operatorname{trn} L-U A A, \operatorname{trn} L-U A G, \operatorname{trn} M-C A U, \operatorname{trn} N-G U U(\times 2), \\
\operatorname{trn} P-U G G, \operatorname{trn} Q-U U G, \operatorname{trn} R-A C G(\times 2), \operatorname{trn} R-U C U, \operatorname{trn} S-G C U, \operatorname{trn} S-G G A, \\
\operatorname{trn} S-U G A, \operatorname{trn} T-G G U, \operatorname{trn} T-U G U, \operatorname{trn} V-G A C(\times 2), \operatorname{trn} V-U A C, \operatorname{trrn} W-C C A, \\
\operatorname{trn} Y-G U A,\end{array}$ \\
\hline & $\begin{array}{l}\text { 核糖体小亚基基因 Small } \\
\text { subunit of ribosome }\end{array}$ & $\begin{array}{l}\text { rps } 2, r p s 3, r p s 4, r p s 7(\times 2), r p s 8, r p s 11, r p s 12, r p s 14, r p s 15, r p s 16, r p s 18, \\
\text { rps } 19, \text { rpoA, rpoB, rpoC1, rpoC2 }\end{array}$ \\
\hline & $\begin{array}{l}\text { 核糖体大亚基基因 Large } \\
\text { subunit of ribosome }\end{array}$ & rpl2(×2), rpl14, rpl16, rpl20, rpl22, rpl23(×2), rpl32, rpl33, rpl36 \\
\hline $\begin{array}{l}\text { 光合作用相关 } \\
\text { 基因 }\end{array}$ & $\begin{array}{l}\text { ATP 酶合成基因 ATP } \\
\text { synthase gene }\end{array}$ & atpA, atpB, atpE, atpF, atpH, atpI \\
\hline \multirow[t]{10}{*}{ Photosynthesis } & $\begin{array}{l}\text { 装配/稳定光系统 I 基因 } \\
\text { Assembly/stability of } \\
\text { photosystem I }\end{array}$ & $y c f 3, y c f 4$ \\
\hline & $\begin{array}{l}\text { 细胞色素复合物基因 } \\
\text { Cytochrome b/f complex }\end{array}$ & petA, pet $B, \operatorname{pet} D, \operatorname{pet} G, \operatorname{pet} L, \operatorname{pet} N$ \\
\hline & $\begin{array}{l}\mathrm{c} \text { 型细胞色素合成基因 c- } \\
\text { type cytochrome synthesis } \\
\text { ccsA gene }\end{array}$ & $\operatorname{ccs} A$ \\
\hline & NADH 脱氢酶基因 & $n d h A, n d h B(\times 2), n d h C, n d h D, n d h E, n d h F, n d h G, n d h H, n d h I, n d h J, n d h K$ \\
\hline & NADPH dehydrogenase & \\
\hline & 光合系统 I 基因 & psaA,psaB, psaC, psaI, psaJ \\
\hline & Photosystem I & \\
\hline & 光合系统 II 基因 & $p s b A, p s b B, p s b C, p s b D, p s b E, p s b F, p s b H, p s b I, p s b J, p s b K, p s b L, p s b M$ \\
\hline & Photosystem II & $p s b N, p s b T, p s b Z$ \\
\hline & $\begin{array}{l}\text { 二磷酸核酮糖羧化酶大亚 } \\
\text { 基基因 RubisCO large } \\
\text { subunit }\end{array}$ & $r b c L$ \\
\hline 其他基因 & 蛋白水解作用基因 & $\operatorname{clp} P$ \\
\hline \multirow[t]{7}{*}{ Other genes } & Proteolysis & \\
\hline & 成熟酶基因 Maturase & matK \\
\hline & $\begin{array}{l}\text { 包裹膜蛋白基因 Envelop } \\
\text { membrane protein }\end{array}$ & cemA \\
\hline & $\begin{array}{l}\text { 乙酰辅酶 A 羧化酶亚基 } \\
\text { 基因 Subunit of acetyl- } \\
\text { CoA-carboxylase }\end{array}$ & $a c c D$ \\
\hline & $\begin{array}{l}\text { 转录起始因子基因 } \\
\text { Transcription initiation } \\
\text { factor IF-1 }\end{array}$ & $\operatorname{Inf} A$ \\
\hline & $\begin{array}{l}\text { TIC 复合体组成基因 } \\
\text { Component of TIC } \\
\text { complex }\end{array}$ & $y c f 1$ \\
\hline & $\begin{array}{l}\text { 假定叶绿体阅读框 } \\
\text { Hypothetical chloroplast } \\
\text { reading frames }\end{array}$ & $y c f 2(\times 2), y c f 15(\times 2)$ \\
\hline
\end{tabular}


陆奇丰, 黄至欢, 骆文华 (2021) 极小种群濒危植物广西火桐、丹霞梧桐的叶绿体基因组特征. 生物多样性, 29(5), 586-595. http://www.biodiversity-science.net/CN/10.17520/biods.2020263

附录 2 广西火桐和丹霞梧桐的叶绿体基因组 SSR 信息。 $\mathrm{p} 1$ 为单核苷酸重复类型; $\mathrm{p} 2$ 为双核苷酸重复类 型; $\mathrm{p} 3$ 为三核苷酸重复类型; $\mathrm{p} 4$ 为四核苷酸重复类型; $\mathrm{p} 5$ 为五核苷酸重复类型; $\mathrm{c}$ 为复合核苷酸类型。

Appendix 2 SSR sequences identified in Firmiana kwangsiensis and F. danxiaensis chloroplast genome. p1, mononucleotide; p2, dinucleotide; p3, trinucleotide; p4, tetranucleotide; p5, pentanucleotide; c, composite nucleotide.

\begin{tabular}{|c|c|c|c|c|c|c|c|}
\hline 序号 & 重复类型 & 简单重复序列 & 大小 & 起始 & 终止 & 分布位置 & 分布区域 \\
\hline Code & SSR type & SSR seqeunce & Size & Start & End & Location & Region \\
\hline
\end{tabular}

\begin{tabular}{|c|c|c|c|c|c|c|c|}
\hline \multicolumn{8}{|c|}{ 广西火桐 Firmiana kwangsiensis } \\
\hline 1 & $\mathrm{p} 1$ & $(\mathrm{~T}) 11$ & 11 & 1537 & 1547 & IGS & LSC \\
\hline 2 & $\mathrm{p} 1$ & (A) 11 & 11 & 3742 & 3752 & $t R N A-L y s$ (intron) & LSC \\
\hline 3 & $\mathrm{p} 1$ & (A) 12 & 12 & 4264 & 4275 & IGS & LSC \\
\hline 4 & $\mathrm{p} 1$ & (C) 10 & 10 & 5403 & 5412 & rps16 (intron) & LSC \\
\hline 5 & $\mathrm{c}$ & (A) $12 \ldots(\mathrm{A}) 10$ & 78 & 5567 & 5644 & rps16 (intron) & LSC \\
\hline 6 & $\mathrm{p} 1$ & (A) 12 & 12 & 6785 & 6796 & IGS & LSC \\
\hline 7 & $\mathrm{p} 1$ & (A) 10 & 10 & 7486 & 7495 & IGS & LSC \\
\hline 8 & $\mathrm{c}$ & (A) $10(\mathrm{G}) 10$ & 20 & 7965 & 7984 & psbI IGS & LSC \\
\hline 9 & $\mathrm{p} 4$ & $($ TTAT)3 & 12 & 8223 & 8234 & IGS & LSC \\
\hline 10 & $\mathrm{p} 1$ & (A) 12 & 12 & 8436 & 8447 & IGS & LSC \\
\hline 11 & $\mathrm{p} 1$ & (A) 10 & 10 & 8756 & 8765 & IGS & LSC \\
\hline 12 & $\mathrm{p} 1$ & $(\mathrm{~T}) 12$ & 12 & 9357 & 9368 & $t R N A-G l y$ (intron) & LSC \\
\hline 13 & $\mathrm{p} 1$ & $(\mathrm{~T}) 11$ & 11 & 9664 & 9674 & $t R N A-G l y$ (intron) & LSC \\
\hline 14 & $\mathrm{p} 4$ & (TCTA)3 & 12 & 9830 & 9841 & IGS & LSC \\
\hline 15 & $\mathrm{p} 1$ & $(\mathrm{~T}) 11$ & 11 & 12282 & 12292 & $a t p F$ (intron) & LSC \\
\hline 16 & $\mathrm{p} 1$ & (C) 11 & 11 & 14616 & 14626 & IGS & LSC \\
\hline 17 & $\mathrm{p} 4$ & $(\mathrm{ATAA}) 3$ & 12 & 15037 & 15048 & IGS & LSC \\
\hline 18 & $\mathrm{p} 1$ & (A) 10 & 10 & 16047 & 16056 & IGS & LSC \\
\hline 19 & $\mathrm{c}$ & (T) $12 \ldots(\mathrm{A}) 10$ & 25 & 16966 & 16990 & IGS & LSC \\
\hline 20 & $\mathrm{p} 1$ & $(\mathrm{~T}) 10$ & 10 & 17325 & 17334 & rрос2 & LSC \\
\hline 21 & $\mathrm{p} 1$ & $(\mathrm{~T}) 10$ & 10 & 19236 & 19245 & rpoc2 & LSC \\
\hline 22 & $\mathrm{p} 1$ & $(\mathrm{~T}) 11$ & 11 & 21663 & 21673 & rpoC1 & LSC \\
\hline 23 & $\mathrm{c}$ & (C)11(A)11 & 22 & 23298 & 23319 & rpoCl (intron) & LSC \\
\hline 24 & $\mathrm{p} 1$ & $(\mathrm{~T}) 12$ & 12 & 26974 & 26985 & rрoв & LSC \\
\hline 25 & $\mathrm{p} 1$ & (A) 10 & 10 & 27909 & 27918 & IGS & LSC \\
\hline 26 & $\mathrm{p} 1$ & (A) 11 & 11 & 28533 & 28543 & IGS & LSC \\
\hline 27 & $\mathrm{c}$ & (A)11...(T)10 & 37 & 30246 & 30282 & IGS & LSC \\
\hline 28 & $\mathrm{p} 2$ & $(\mathrm{AT}) 5$ & 10 & 30616 & 30625 & IGS & LSC \\
\hline 29 & $\mathrm{p} 2$ & (TA) 5 & 10 & 32371 & 32380 & IGS & LSC \\
\hline 30 & $\mathrm{c}$ & (A)10...(T)11 & 77 & 32557 & 32633 & IGS & LSC \\
\hline 31 & $\mathrm{p} 2$ & (TA) 5 & 10 & 32918 & 32927 & IGS & LSC \\
\hline 32 & $\mathrm{c}$ & $($ TGAAA)3...(AT)5 & 103 & 33909 & 34011 & IGS & LSC \\
\hline 33 & $\mathrm{p} 1$ & $(\mathrm{~T}) 14$ & 14 & 34331 & 34344 & IGS & LSC \\
\hline 34 & $\mathrm{p} 1$ & (A) 10 & 10 & 38021 & 38030 & IGS & LSC \\
\hline
\end{tabular}


陆奇丰, 黄至欢, 骆文华 (2021) 极小种群濒危植物广西火桐、丹霞梧桐的叶绿体基因组特征. 生物多样性, 29(5), 586-595. http://www.biodiversity-science.net/CN/10.17520/biods.2020263

\begin{tabular}{|c|c|c|c|c|c|c|c|}
\hline 序号 & 重复类型 & 简单重复序列 & 大小 & 起始 & 终止 & 分布位置 & 分布区域 \\
\hline Code & SSR type & SSR seqeunce & Size & Start & End & Location & Region \\
\hline \multicolumn{8}{|c|}{ 广西火桐 Firmiana kwangsiensis } \\
\hline 35 & $\mathrm{p} 4$ & (ATCT)3 & 12 & 44132 & 44143 & IGS & LSC \\
\hline 36 & $\mathrm{c}$ & (T) $10 \ldots(\mathrm{A}) 12$ & 95 & 46737 & 46831 & $y c f 3$ (intron) & LSC \\
\hline 37 & $\mathrm{p} 2$ & $(\mathrm{AT}) 8$ & 16 & 47104 & 47119 & IGS & LSC \\
\hline 38 & $\mathrm{p} 1$ & (A) 10 & 10 & 50346 & 50355 & IGS & LSC \\
\hline 39 & $\mathrm{p} 4$ & $(\mathrm{AAAT}) 3$ & 12 & 50618 & 50629 & IGS & LSC \\
\hline 40 & $\mathrm{p} 2$ & $(\mathrm{AT}) 5$ & 10 & 51486 & 51495 & IGS & LSC \\
\hline 41 & $\mathrm{c}$ & (T)10...(TAT) 4 & 65 & 51888 & 51952 & IGS & LSC \\
\hline 42 & $\mathrm{c}$ & $(\mathrm{TATT}) 3 \ldots(\mathrm{TA}) 5$ & 110 & 54619 & 54728 & IGS & LSC \\
\hline 43 & $\mathrm{p} 1$ & (T) 10 & 10 & 55001 & 55010 & IGS & LSC \\
\hline 44 & $\mathrm{p} 1$ & $(\mathrm{~T}) 11$ & 11 & 58571 & 58581 & IGS & LSC \\
\hline 45 & $\mathrm{p} 1$ & $(\mathrm{~T}) 10$ & 10 & 58921 & 58930 & IGS & LSC \\
\hline 46 & $\mathrm{p} 4$ & $(\mathrm{TAGT}) 3$ & 12 & 63084 & 63095 & IGS & LSC \\
\hline 47 & $\mathrm{p} 2$ & $(\mathrm{AT}) 5$ & 10 & 65694 & 65703 & IGS & LSC \\
\hline 48 & $\mathrm{p} 2$ & (TC) 5 & 10 & 65996 & 66005 & cemA & LSC \\
\hline 49 & $\mathrm{p} 4$ & $(\mathrm{AGGA}) 3$ & 12 & 68124 & 68135 & IGS & LSC \\
\hline 50 & $\mathrm{p} 1$ & (A) 16 & 16 & 68576 & 68591 & IGS & LSC \\
\hline 51 & $\mathrm{p} 1$ & $(\mathrm{~T}) 11$ & 11 & 69157 & 69167 & IGS & LSC \\
\hline 52 & $\mathrm{p} 1$ & (A) 15 & 15 & 70244 & 70258 & IGS & LSC \\
\hline 53 & $\mathrm{p} 1$ & $(\mathrm{~T}) 12$ & 12 & 71046 & 71057 & IGS & LSC \\
\hline 54 & $\mathrm{p} 4$ & (TATT)3 & 12 & 72353 & 72364 & IGS & LSC \\
\hline 55 & $\mathrm{c}$ & $(\mathrm{TAT}) 4 \ldots(\mathrm{TAT}) 4$ & 33 & 72855 & 72887 & IGS & LSC \\
\hline 56 & $\mathrm{p} 4$ & $(\mathrm{AAAT}) 3$ & 12 & 73525 & 73536 & IGS & LSC \\
\hline 57 & $\mathrm{c}$ & (T)13...(T)10 & 103 & 75608 & 75710 & $\operatorname{clp} P$ (intron) & LSC \\
\hline 58 & $\mathrm{p} 1$ & (A) 10 & 10 & 75834 & 75843 & $c l p P$ (intron) & LSC \\
\hline 59 & $\mathrm{p} 1$ & $(\mathrm{~T}) 10$ & 10 & 76541 & 76550 & $c l p P$ (intron) & LSC \\
\hline 60 & $\mathrm{p} 1$ & (A) 12 & 12 & 76879 & 76890 & $\operatorname{clp} P$ (intron) & LSC \\
\hline 61 & p3 & (ATT)4 & 12 & 79680 & 79691 & $p s b N$ & LSC \\
\hline 62 & $\mathrm{p} 1$ & (A) 10 & 10 & 80328 & 80337 & petB (intron) & LSC \\
\hline 63 & $\mathrm{p} 1$ & (A) 11 & 11 & 81702 & 81712 & IGS & LSC \\
\hline 64 & $\mathrm{p} 1$ & $(\mathrm{~T}) 11$ & 11 & 82061 & 82071 & petD (intron) & LSC \\
\hline 65 & $\mathrm{p} 1$ & (A) 10 & 10 & 83043 & 83052 & IGS & LSC \\
\hline 66 & $\mathrm{p} 1$ & $(\mathrm{~T}) 14$ & 14 & 83175 & 83188 & IGS & LSC \\
\hline 67 & $\mathrm{p} 1$ & $(\mathrm{~T}) 11$ & 11 & 85400 & 85410 & IGS & LSC \\
\hline 68 & $\mathrm{p} 1$ & (A) 10 & 10 & 86443 & 86452 & IGS & LSC \\
\hline 69 & $\mathrm{p} 4$ & (TTTA)3 & 12 & 87529 & 87540 & rpl16 (intron) & LSC \\
\hline 70 & $\mathrm{p} 1$ & $(\mathrm{~T}) 11$ & 11 & 88001 & 88011 & rpl16 (intron) & LSC \\
\hline 71 & $\mathrm{c}$ & $(\mathrm{T}) 13 \ldots(\mathrm{TA}) 5$ & 115 & 89706 & 89820 & IGS & $\mathrm{IRb}$ \\
\hline 72 & $\mathrm{p} 1$ & $(\mathrm{~T}) 11$ & 11 & 104784 & 104794 & IGS & $\mathrm{IRb}$ \\
\hline
\end{tabular}


陆奇丰, 黄至欢, 骆文华 (2021) 极小种群濒危植物广西火桐、丹霞梧桐的叶绿体基因组特征. 生物多样性, 29(5), 586-595. http://www.biodiversity-science.net/CN/10.17520/biods.2020263

\begin{tabular}{|c|c|c|c|c|c|c|c|}
\hline 序号 & 重复类型 & 简单重复序列 & 大小 & 起始 & 终止 & 分布位置 & 分布区域 \\
\hline Code & SSR type & SSR seqeunce & Size & Start & End & Location & Region \\
\hline \multicolumn{8}{|c|}{ 广西火桐 Firmiana kwangsiensis } \\
\hline 73 & p5 & (TATTA)3 & 15 & 105351 & 105365 & IGS & $\mathrm{IRb}$ \\
\hline 74 & p5 & (TAAAG)3 & 15 & 110451 & 110465 & IGS & $\mathrm{IRb}$ \\
\hline 75 & $\mathrm{p} 1$ & (A) 15 & 15 & 113928 & 113942 & IGS & $\mathrm{IRb}$ \\
\hline 76 & $\mathrm{p} 1$ & (A) 11 & 11 & 115362 & 115372 & IGS & SSC \\
\hline 77 & $\mathrm{c}$ & $(\mathrm{T}) 12 \ldots(\mathrm{T}) 11$ & 68 & 118215 & 118282 & IGS & SSC \\
\hline 78 & $\mathrm{p} 1$ & $(\mathrm{~T}) 10$ & 10 & 118644 & 118653 & IGS & SSC \\
\hline 79 & $\mathrm{p} 3$ & $(\mathrm{AAT}) 4$ & 12 & 118809 & 118820 & IGS & SSC \\
\hline 80 & $\mathrm{p} 1$ & $(\mathrm{~T}) 11$ & 11 & 121062 & 121072 & IGS & SSC \\
\hline 81 & $\mathrm{p} 4$ & (TTGA)3 & 12 & 123353 & 123364 & $n d h E$ & SSC \\
\hline 82 & p5 & $($ TAGAA) 3 & 15 & 123718 & 123732 & IGS & SSC \\
\hline 83 & $\mathrm{p} 1$ & $(\mathrm{~T}) 12$ & 12 & 124459 & 124470 & IGS & SSC \\
\hline 84 & $c^{*}$ & (AATA) $2 \ldots$ (A) 9 & 21 & 126167 & 126187 & $n d h A$ (intron) & SSC \\
\hline 85 & $\mathrm{p} 1$ & (A) 11 & 11 & 126400 & 126410 & $n d h A$ (intron) & SSC \\
\hline 86 & $\mathrm{p} 1$ & $(\mathrm{~T}) 11$ & 11 & 126914 & 126924 & $n d h A$ (intron) & SSC \\
\hline 87 & $\mathrm{p} 1$ & $(\mathrm{~T}) 10$ & 10 & 131271 & 131280 & $y c f 1$ & SSC \\
\hline 88 & $\mathrm{p} 4$ & $(\mathrm{CATT}) 3$ & 12 & 131445 & 131456 & $y c f 1$ & SSC \\
\hline 89 & $\mathrm{p} 1$ & $(\mathrm{~T}) 11$ & 11 & 132436 & 132446 & $y c f 1$ & SSC \\
\hline 90 & $\mathrm{p} 1$ & $(\mathrm{~T}) 11$ & 11 & 133686 & 133696 & $y c f 1$ & SSC \\
\hline 91 & $\mathrm{p} 1$ & $(\mathrm{~T}) 10$ & 10 & 134216 & 134225 & $y c f 1$ & SSC \\
\hline 92 & $\mathrm{p} 1$ & $(\mathrm{~T}) 13$ & 13 & 134335 & 134347 & $y c f 1$ & SSC \\
\hline 93 & $\mathrm{p} 1$ & (C) 11 & 11 & 134464 & 134474 & $y c f 1$ & SSC \\
\hline 94 & $\mathrm{p} 1$ & $(\mathrm{~T}) 15$ & 15 & 136595 & 136609 & IGS & $\mathrm{IRa}$ \\
\hline 95 & p5 & $($ ACTTT) 3 & 15 & 140071 & 140085 & IGS & $\mathrm{IRa}$ \\
\hline 96 & $\mathrm{p} 5$ & (TAATA) 3 & 15 & 145172 & 145186 & IGS & IRa \\
\hline 97 & $\mathrm{p} 1$ & (A) 11 & 11 & 145743 & 145753 & IGS & $\mathrm{IRa}$ \\
\hline 98 & $\mathrm{c}$ & $(\mathrm{AT}) 5 \ldots(\mathrm{A}) 13$ & 116 & 160716 & 160831 & IGS & IRa \\
\hline \multicolumn{8}{|c|}{ 丹霞梧桐 Firmiana danxiaensis } \\
\hline 1 & $\mathrm{p} 1$ & $(\mathrm{~T}) 12$ & 12 & 1535 & 1546 & IGS & LSC \\
\hline 2 & $\mathrm{p} 1$ & (A) 10 & 10 & 3752 & 3761 & tRNA-Lys (intron) & LSC \\
\hline 3 & $\mathrm{p} 1$ & (A) 10 & 10 & 4306 & 4315 & IGS & LSC \\
\hline 4 & $\mathrm{p} 1$ & $(\mathrm{~T}) 10$ & 10 & 4511 & 4520 & IGS & LSC \\
\hline 5 & $\mathrm{c}$ & (T) $10 \ldots$ (TTTTTA) 3 & 49 & 4779 & 4827 & IGS & LSC \\
\hline 6 & $\mathrm{p} 1$ & (A) 14 & 14 & 5606 & 5619 & rps16 (intron) & LSC \\
\hline 7 & $\mathrm{p} 1$ & (A) 13 & 13 & 6754 & 6766 & IGS & LSC \\
\hline 8 & $\mathrm{p} 1$ & (A) 10 & 10 & 7445 & 7454 & IGS & LSC \\
\hline 9 & $\mathrm{p} 4$ & $($ TTAT)3 & 12 & 8175 & 8186 & IGS & LSC \\
\hline 10 & $\mathrm{p} 1$ & $(\mathrm{~T}) 10$ & 10 & 9181 & 9190 & tRNA-Gly (intron) & LSC \\
\hline 11 & $\mathrm{p} 1$ & $(\mathrm{~T}) 10$ & 10 & 9587 & 9596 & tRNA-Gly (intron) & LSC \\
\hline
\end{tabular}


陆奇丰, 黄至欢, 骆文华 (2021) 极小种群濒危植物广西火桐、丹霞梧桐的叶绿体基因组特征. 生物多样性, 29(5), 586-595. http://www.biodiversity-science.net/CN/10.17520/biods.2020263

\begin{tabular}{|c|c|c|c|c|c|c|c|}
\hline 序号 & 重复类型 & 简单重复序列 & 大小 & 起始 & 终止 & 分布位置 & 分布区域 \\
\hline Code & SSR type & SSR seqeunce & Size & Start & End & Location & Region \\
\hline 12 & $\mathrm{p} 4$ & (TCTA)3 & 12 & 9756 & 9767 & IGS & LSC \\
\hline 13 & $\mathrm{p} 1$ & $(\mathrm{~T}) 11$ & 11 & 12320 & 12330 & atpF (intron) & LSC \\
\hline 14 & $\mathrm{p} 1$ & $(\mathrm{~T}) 10$ & 10 & 12437 & 12446 & atpF (intron) & LSC \\
\hline 15 & $\mathrm{p} 1$ & (T) 10 & 10 & 12696 & 12705 & atpF (intron) & LSC \\
\hline 16 & $\mathrm{p} 1$ & $(\mathrm{~T}) 10$ & 10 & 13534 & 13543 & IGS & LSC \\
\hline 17 & $\mathrm{p} 1$ & (C) 14 & 14 & 14646 & 14659 & IGS & LSC \\
\hline 18 & $\mathrm{c}$ & $(\mathrm{ATAA}) 4(\mathrm{~A}) 10$ & 24 & 15062 & 15085 & IGS & LSC \\
\hline 19 & $\mathrm{p} 1$ & (A) 11 & 11 & 16079 & 16089 & IGS & LSC \\
\hline 20 & $\mathrm{p} 1$ & (A) 13 & 13 & 17011 & 17023 & IGS & LSC \\
\hline 21 & $\mathrm{p} 1$ & (T) 10 & 10 & 17358 & 17367 & rрос2 & LSC \\
\hline 22 & $\mathrm{p} 1$ & (T) 11 & 11 & 19268 & 19278 & rрос2 & LSC \\
\hline 23 & $\mathrm{p} 2$ & $(\mathrm{AT}) 5$ & 10 & 20647 & 20656 & rрос2 & LSC \\
\hline 24 & $\mathrm{p} 1$ & $(\mathrm{~T}) 11$ & 11 & 21696 & 21706 & rpoCl & LSC \\
\hline 25 & $\mathrm{p} 1$ & $(\mathrm{~T}) 12$ & 12 & 27009 & 27020 & rрoв & LSC \\
\hline 26 & $\mathrm{p} 1$ & (A) 11 & 11 & 27944 & 27954 & IGS & LSC \\
\hline 27 & $\mathrm{p} 1$ & (T) 10 & 10 & 30335 & 30344 & IGS & LSC \\
\hline 28 & $\mathrm{p} 2$ & $(\mathrm{AT}) 5$ & 10 & 30672 & 30681 & IGS & LSC \\
\hline 29 & $\mathrm{p} 1$ & $(\mathrm{~T}) 10$ & 10 & 30921 & 30930 & IGS & LSC \\
\hline 30 & $\mathrm{p} 1$ & (A) 16 & 16 & 31947 & 31962 & IGS & LSC \\
\hline 31 & $\mathrm{p} 2$ & (TA) 6 & 12 & 32426 & 32437 & IGS & LSC \\
\hline 32 & $\mathrm{p} 1$ & (T) 17 & 17 & 32673 & 32689 & IGS & LSC \\
\hline 33 & $\mathrm{p} 2$ & (TA) 5 & 10 & 32974 & 32983 & IGS & LSC \\
\hline 34 & c & $(\mathrm{TGAAA}) 3 \ldots(\mathrm{AT}) 5$ & 112 & 33975 & 34086 & IGS & LSC \\
\hline 35 & $\mathrm{p} 1$ & (T) 12 & 12 & 34406 & 34417 & IGS & LSC \\
\hline 36 & $\mathrm{p} 1$ & (T) 10 & 10 & 37119 & 37128 & IGS & LSC \\
\hline 37 & $\mathrm{p} 1$ & (A) 10 & 10 & 37983 & 37992 & IGS & LSC \\
\hline 38 & $\mathrm{p} 4$ & $(\mathrm{ATCT}) 3$ & 12 & 44185 & 44196 & IGS & LSC \\
\hline 39 & $\mathrm{p} 2$ & $(\mathrm{AT}) 5$ & 10 & 44590 & 44599 & IGS & LSC \\
\hline 40 & $\mathrm{p} 1$ & (A) 10 & 10 & 46268 & 46277 & $y c f 3$ (intron) & LSC \\
\hline 41 & $\mathrm{c}$ & $(\mathrm{T}) 14 \ldots(\mathrm{A}) 11$ & 81 & 46804 & 46884 & $y c f 3$ (intron) & LSC \\
\hline 42 & $\mathrm{p} 1$ & (T) 17 & 17 & 47147 & 47163 & IGS & LSC \\
\hline 43 & $\mathrm{p} 1$ & (A) 10 & 10 & 47671 & 47680 & IGS & LSC \\
\hline 44 & $\mathrm{p} 1$ & (T) 10 & 10 & 49240 & 49249 & IGS & LSC \\
\hline 45 & $\mathrm{p} 1$ & $(\mathrm{~T}) 11$ & 11 & 50447 & 50457 & IGS & LSC \\
\hline 46 & $\mathrm{p} 1$ & (A) 10 & 10 & 50807 & 50816 & IGS & LSC \\
\hline 47 & $\mathrm{p} 4$ & $(\mathrm{AAAT}) 3$ & 12 & 51079 & 51090 & IGS & LSC \\
\hline 48 & $\mathrm{p} 1$ & $(\mathrm{~T}) 11$ & 11 & 51510 & 51520 & tRNA-Leu (intron) & LSC \\
\hline 49 & $\mathrm{p} 2$ & $(\mathrm{AT}) 5$ & 10 & 51953 & 51962 & IGS & LSC \\
\hline 50 & $\mathrm{c}$ & (T) $15 \ldots(\mathrm{TAT}) 4$ & 68 & 52355 & 52422 & IGS & LSC \\
\hline
\end{tabular}


陆奇丰, 黄至欢, 骆文华 (2021) 极小种群濒危植物广西火桐、丹霞梧桐的叶绿体基因组特征. 生物多样性, 29(5), 586-595. http://www.biodiversity-science.net/CN/10.17520/biods.2020263

\begin{tabular}{|c|c|c|c|c|c|c|c|}
\hline 序号 & 重复类型 & 简单重复序列 & 大小 & 起始 & 终止 & 分布位置 & 分布区域 \\
\hline Code & SSR type & SSR seqeunce & Size & Start & End & Location & Region \\
\hline 51 & $\mathrm{p} 4$ & (TATT)3 & 12 & 55063 & 55074 & IGS & LSC \\
\hline 52 & $\mathrm{p} 2$ & (TA) 5 & 10 & 55222 & 55231 & IGS & LSC \\
\hline 53 & $\mathrm{p} 1$ & (T) 10 & 10 & 55446 & 55455 & IGS & LSC \\
\hline 54 & $\mathrm{p} 1$ & $(\mathrm{~T}) 13$ & 13 & 59379 & 59391 & IGS & LSC \\
\hline 55 & $\mathrm{c}$ & (TAGT)3...(T)10 & 115 & 63557 & 63671 & IGS & LSC \\
\hline 56 & $\mathrm{p} 1$ & $(\mathrm{~T}) 10$ & 10 & 64443 & 64452 & IGS & LSC \\
\hline 57 & $\mathrm{p} 1$ & $(\mathrm{~T}) 12$ & 12 & 65531 & 65542 & IGS & LSC \\
\hline 58 & $\mathrm{p} 2$ & $(\mathrm{AT}) 5$ & 10 & 66134 & 66143 & IGS & LSC \\
\hline 59 & $\mathrm{p} 2$ & (TC) 5 & 10 & 66436 & 66445 & $\operatorname{cem} A$ & LSC \\
\hline 60 & $\mathrm{p} 1$ & (T) 10 & 10 & 67186 & 67195 & IGS & LSC \\
\hline 61 & $\mathrm{p} 1$ & (A) 11 & 11 & 69013 & 69023 & IGS & LSC \\
\hline 62 & $\mathrm{p} 1$ & (T) 20 & 20 & 71482 & 71501 & IGS & LSC \\
\hline 63 & $\mathrm{p} 1$ & (T) 10 & 10 & 72467 & 72476 & IGS & LSC \\
\hline 64 & $\mathrm{p} 4$ & (TATT)3 & 12 & 72801 & 72812 & IGS & LSC \\
\hline 65 & $\mathrm{c}$ & $(\mathrm{TAT}) 4 \ldots(\mathrm{TA}) 6$ & 80 & 73261 & 73340 & IGS & LSC \\
\hline 66 & $\mathrm{p} 4$ & $(\mathrm{AAAT}) 3$ & 12 & 73909 & 73920 & IGS & LSC \\
\hline 67 & $\mathrm{p} 1$ & (A) 12 & 12 & 75762 & 75773 & $\operatorname{clp} P$ (intron) & LSC \\
\hline 68 & $\mathrm{p} 1$ & $(\mathrm{~T}) 10$ & 10 & 75916 & 75925 & $\operatorname{clpP}$ (intron) & LSC \\
\hline 69 & $\mathrm{p} 1$ & (A)11 & 11 & 76031 & 76041 & $\operatorname{clpP}$ (intron) & LSC \\
\hline 70 & $\mathrm{c}$ & (A) $10 \ldots$ (A) 10 & 25 & 76213 & 76237 & $\operatorname{clp} P$ (intron) & LSC \\
\hline 71 & $\mathrm{p} 1$ & (A) 11 & 11 & 77258 & 77268 & $\operatorname{clp} P$ (intron) & LSC \\
\hline 72 & p3 & (ATT)4 & 12 & 80059 & 80070 & $p s b N$ & LSC \\
\hline 73 & $\mathrm{p} 1$ & (A)11 & 11 & 80707 & 80717 & IGS & LSC \\
\hline 74 & $\mathrm{p} 1$ & (A) 10 & 10 & 82077 & 82086 & IGS & LSC \\
\hline 75 & $\mathrm{p} 1$ & (A) 14 & 14 & 83424 & 83437 & IGS & LSC \\
\hline 76 & $\mathrm{p} 1$ & (T)14 & 14 & 83560 & 83573 & IGS & LSC \\
\hline 77 & $\mathrm{p} 1$ & $(\mathrm{~T}) 11$ & 11 & 85806 & 85816 & IGS & LSC \\
\hline 78 & $\mathrm{p} 1$ & (T) 10 & 10 & 86315 & 86324 & IGS & LSC \\
\hline 79 & $\mathrm{p} 1$ & (A) 10 & 10 & 86851 & 86860 & IGS & LSC \\
\hline 80 & p5 & $(\mathrm{AAAAT}) 3$ & 15 & 87990 & 88004 & IGS & LSC \\
\hline 81 & $\mathrm{p} 1$ & (T) 10 & 10 & 88423 & 88432 & IGS & LSC \\
\hline 82 & $\mathrm{p} 2$ & (TA) 7 & 14 & 90205 & 90218 & IGS & LSC \\
\hline 83 & $\mathrm{p} 1$ & $(\mathrm{~T}) 12$ & 12 & 105151 & 105162 & IGS & $\mathrm{IRb}$ \\
\hline 84 & p5 & (TATTA)3 & 15 & 105719 & 105733 & IGS & $\mathrm{IRb}$ \\
\hline 85 & $\mathrm{p} 5$ & (TAAAG)3 & 15 & 110818 & 110832 & IGS & $\mathrm{IRb}$ \\
\hline 86 & $\mathrm{p} 1$ & (A) 19 & 19 & 114289 & 114307 & $r r n 5$ & $\mathrm{IRb}$ \\
\hline 87 & $\mathrm{p} 5$ & $(\mathrm{AGAAA}) 3$ & 15 & 115599 & 115613 & IGS & $\mathrm{IRb}$ \\
\hline 88 & $\mathrm{c}$ & (A) $10 \ldots(\mathrm{T}) 18$ & 34 & 118309 & 118342 & IGS & $\mathrm{SSC}$ \\
\hline 89 & p5 & (TAGAA)3 & 15 & 118721 & 118735 & IGS & SSC \\
\hline
\end{tabular}


陆奇丰, 黄至欢, 骆文华 (2021) 极小种群濒危植物广西火桐、丹霞梧桐的叶绿体基因组特征. 生物多样性, 29(5), 586-595. http://www.biodiversity-science.net/CN/10.17520/biods.2020263

\begin{tabular}{|c|c|c|c|c|c|c|c|}
\hline 序号 & 重复类型 & 简单重复序列 & 大小 & 起始 & 终止 & 分布位置 & 分布区域 \\
\hline Code & SSR type & SSR seqeunce & Size & Start & End & Location & Region \\
\hline 90 & c & $(\mathrm{AT}) 6(\mathrm{~T}) 10$ & 21 & 119151 & 119171 & IGS & $\mathrm{SSC}$ \\
\hline 91 & $\mathrm{c}$ & (T)10...(T)15 & 60 & 121528 & 121587 & IGS & SSC \\
\hline 92 & $\mathrm{p} 4$ & (TTGA)3 & 12 & 123799 & 123810 & $n d h E$ & SSC \\
\hline 93 & p5 & (TAGAA)3 & 15 & 124164 & 124178 & IGS & SSC \\
\hline 94 & $\mathrm{c}$ & (AATA)(A) 10 & 21 & 126610 & 126630 & $n d h A$ (intron) & SSC \\
\hline 95 & $\mathrm{c}$ & (A) $10 \ldots$ (A) 10 & 95 & 126759 & 126853 & $n d h A$ (intron) & SSC \\
\hline 96 & $\mathrm{p} 1$ & (T) 10 & 10 & 131719 & 131728 & $y c f 1$ & SSC \\
\hline 97 & $\mathrm{p} 4$ & (CATT) 3 & 12 & 131893 & 131904 & $y c f 1$ & SSC \\
\hline 98 & $\mathrm{p} 1$ & (T) 11 & 11 & 132884 & 132894 & $y c f 1$ & SSC \\
\hline 99 & $\mathrm{p} 1$ & (T) 11 & 11 & 134161 & 134171 & $y c f 1$ & SSC \\
\hline 100 & $\mathrm{p} 1$ & (T) 10 & 10 & 134691 & 134700 & $y c f 1$ & SSC \\
\hline 101 & $\mathrm{p} 1$ & (T) 13 & 13 & 134810 & 134822 & $y c f 1$ & SSC \\
\hline 102 & $\mathrm{p} 5$ & (TTTTC)3 & 15 & 135782 & 135796 & IGS & SSC \\
\hline 103 & $\mathrm{p} 1$ & (T) 19 & 19 & 137089 & 137107 & $r r n 5$ & IRa \\
\hline 104 & $\mathrm{p} 5$ & $(\mathrm{ACTTT}) 3$ & 15 & 140563 & 140577 & IGS & IRa \\
\hline 105 & $\mathrm{p} 5$ & (TAATA)3 & 15 & 145663 & 145677 & IGS & IRa \\
\hline 106 & $\mathrm{p} 1$ & (A) 12 & 12 & 146234 & 146245 & IGS & IRa \\
\hline 107 & $\mathrm{p} 2$ & (AT)7 & 14 & 161177 & 161190 & IGS & IRa \\
\hline
\end{tabular}


陆奇丰, 黄至欢, 骆文华 (2021) 极小种群濒危植物广西火桐、丹霞梧桐的叶绿体基因组特征. 生物多样性, 29(5), 586-595. http://www.biodiversity-science.net/CN/10.17520/biods.2020263

附录 3 广西火桐和丹霞梧桐的叶绿体基因组重复序列。注: $\mathrm{F}$ 为正向重复序列; $\mathrm{R}$ 为反向重复序列; $\mathrm{P}$ 为 回文重复序列。

Appendix 3 The repeat sequences identified in Firmiana kwangsiensis and F. danxiaensis chloroplast genome.

The $\mathrm{F}$ means forward sequence, $\mathrm{R}$ means reverse sequence and $\mathrm{P}$ means palindromic sequence.

\begin{tabular}{|c|c|c|c|c|c|c|}
\hline $\begin{array}{l}\text { 序列长度 } \\
\text { Length (bp) }\end{array}$ & $\begin{array}{l}\text { 重复类型 } \\
\text { Repeat type }\end{array}$ & $\begin{array}{l}\text { 重复 } 1 \text { 起始位点 } \\
\text { Repeat } 1 \text { start } \\
\text { position }\end{array}$ & $\begin{array}{l}\text { 重复 } 1 \text { 位置 } \\
\text { Repeat } 1 \\
\text { location }\end{array}$ & $\begin{array}{l}\text { 重复 } 2 \text { 起始位点 } \\
\text { Repeat } 2 \text { start } \\
\text { position }\end{array}$ & $\begin{array}{l}\text { 重复 } 2 \text { 位置 } \\
\text { Repeat } 2 \text { location }\end{array}$ & $\begin{array}{l}\mathrm{E} \text { 值 } \\
\mathrm{E} \text { value }\end{array}$ \\
\hline \multicolumn{7}{|c|}{ 广西火桐 Firmiana kwangsiensis } \\
\hline 45 & $\mathrm{P}$ & 4362 & IGS & 4362 & IGS & $7.93 \mathrm{E}-16$ \\
\hline 65 & $\mathrm{~F}$ & 4752 & IGS & 4779 & IGS & $6.30 \mathrm{E}-24$ \\
\hline 38 & $\mathrm{~F}$ & 4752 & IGS & 4806 & IGS & $2.19 \mathrm{E}-08$ \\
\hline 30 & $\mathrm{P}$ & 8048 & $t R N A-G C U$ & 48024 & $\operatorname{trn} S-G G A$ & $5.68 \mathrm{E}-07$ \\
\hline 35 & $\mathrm{P}$ & 16961 & IGS & 16961 & IGS & $1.09 \mathrm{E}-06$ \\
\hline 49 & $\mathrm{~F}$ & 40893 & $\operatorname{psaB}$ & 43117 & psaA & $2.43 \mathrm{E}-16$ \\
\hline 41 & $\mathrm{~F}$ & 40901 & $p s a B$ & 43125 & $p s a A$ & $1.85 \mathrm{E}-13$ \\
\hline 30 & $\mathrm{R}$ & 44132 & IGS & 44132 & IGS & $2.47 \mathrm{E}-05$ \\
\hline 30 & $\mathrm{P}$ & 44521 & IGS & 44521 & IGS & $2.47 \mathrm{E}-05$ \\
\hline 41 & $\mathrm{~F}$ & 46143 & $y c f 3$ intron & 125994 & ndhA intron & $4.33 \mathrm{E}-10$ \\
\hline 36 & $\mathrm{~F}$ & 46148 & $y c f 3$ intron & 104382 & IGS & $1.66 \mathrm{E}-10$ \\
\hline 36 & $\mathrm{P}$ & 46148 & $y c f 3$ intron & 146118 & IGS & $1.66 \mathrm{E}-10$ \\
\hline 30 & $\mathrm{~F}$ & 46157 & $y c f 3$ intron & 104391 & IGS & $5.68 \mathrm{E}-07$ \\
\hline 30 & $\mathrm{P}$ & 46157 & $y c f 3$ intron & 146115 & IGS & $5.68 \mathrm{E}-07$ \\
\hline 30 & $\mathrm{~F}$ & 49729 & IGS & 49771 & IGS & $2.47 \mathrm{E}-05$ \\
\hline 31 & $\mathrm{~F}$ & 63398 & IGS & 63430 & IGS & $1.58 \mathrm{E}-09$ \\
\hline 49 & $\mathrm{~F}$ & 72823 & IGS & 72844 & IGS & $3.37 \mathrm{E}-18$ \\
\hline 32 & $\mathrm{~F}$ & 72823 & IGS & 72865 & IGS & $1.76 \mathrm{E}-06$ \\
\hline 32 & $\mathrm{~F}$ & 72844 & IGS & 72865 & IGS & $3.79 \mathrm{E}-08$ \\
\hline 34 & $\mathrm{R}$ & 76828 & clpP intron & 76828 & clpP intron & $1.24 \mathrm{E}-07$ \\
\hline 48 & $\mathrm{P}$ & 79503 & IGS & 79503 & IGS & $9.18 \mathrm{E}-20$ \\
\hline 31 & $\mathrm{~F}$ & 94543 & $y c f 2$ & 94564 & $y c f 2$ & $1.47 \mathrm{E}-07$ \\
\hline 31 & $\mathrm{P}$ & 94543 & $y c f 2$ & 155941 & $y c f 2$ & $1.47 \mathrm{E}-07$ \\
\hline 31 & $\mathrm{P}$ & 94564 & $y c f 2$ & 155962 & $y c f 2$ & $1.47 \mathrm{E}-07$ \\
\hline 47 & $\mathrm{~F}$ & 96989 & $y c f 2$ & 97007 & $y c f 2$ & $1.61 \mathrm{E}-13$ \\
\hline 47 & $\mathrm{P}$ & 96989 & $y c f 2$ & 153482 & $y c f 2$ & $1.61 \mathrm{E}-13$ \\
\hline 35 & $\mathrm{~F}$ & 97001 & $y c f 2$ & 97019 & $y c f 2$ & $3.30 \mathrm{E}-08$ \\
\hline 35 & $\mathrm{P}$ & 97001 & $y c f 2$ & 153482 & $y c f 2$ & $3.30 \mathrm{E}-08$ \\
\hline 33 & $\mathrm{~F}$ & 97002 & $y c f 2$ & 97038 & $y c f 2$ & $1.45 \mathrm{E}-05$ \\
\hline 33 & $\mathrm{P}$ & 97002 & $y c f 2$ & 153465 & $y c f 2$ & $1.45 \mathrm{E}-05$ \\
\hline 47 & $\mathrm{P}$ & 97007 & $y c f 2$ & 153500 & $y c f 2$ & $1.61 \mathrm{E}-13$ \\
\hline 35 & $\mathrm{P}$ & 97019 & $y c f 2$ & 153500 & $y c f 2$ & $3.30 \mathrm{E}-08$ \\
\hline 33 & $\mathrm{P}$ & 97038 & $y c f 2$ & 153501 & $y c f 2$ & $1.45 \mathrm{E}-05$ \\
\hline 38 & $\mathrm{~F}$ & 104382 & IGS & 125999 & $n d h A$ intron & $6.09 \mathrm{E}-10$ \\
\hline 30 & $\mathrm{~F}$ & 105325 & IGS & 105352 & IGS & $2.47 \mathrm{E}-05$ \\
\hline
\end{tabular}


陆奇丰, 黄至欢, 骆文华 (2021) 极小种群濒危植物广西火桐、丹霞梧桐的叶绿体基因组特征. 生物多样性, 29(5), 586-595. http://www.biodiversity-science.net/CN/10.17520/biods.2020263

\begin{tabular}{|c|c|c|c|c|c|c|}
\hline $\begin{array}{l}\text { 序列长度 } \\
\text { Length (bp) }\end{array}$ & $\begin{array}{l}\text { 重复类型 } \\
\text { Repeat type }\end{array}$ & $\begin{array}{l}\text { 重复 } 1 \text { 起始位点 } \\
\text { Repeat } 1 \text { start } \\
\text { position }\end{array}$ & $\begin{array}{l}\text { 重复 } 1 \text { 位置 } \\
\text { Repeat } 1 \\
\text { location }\end{array}$ & $\begin{array}{l}\text { 重复 } 2 \text { 起始位点 } \\
\text { Repeat } 2 \text { start } \\
\text { position }\end{array}$ & $\begin{array}{l}\text { 重复 } 2 \text { 位置 } \\
\text { Repeat } 2 \text { location }\end{array}$ & $\begin{array}{l}\mathrm{E} \text { 值 } \\
\text { E value }\end{array}$ \\
\hline \multicolumn{7}{|c|}{ 广西火桐 Firmiana kwangsiensis } \\
\hline 30 & $\mathrm{P}$ & 105325 & IGS & 145154 & IGS & $2.47 \mathrm{E}-05$ \\
\hline 34 & $\mathrm{~F}$ & 113544 & IGS & 113576 & IGS & $1.24 \mathrm{E}-07$ \\
\hline 34 & $\mathrm{P}$ & 113544 & IGS & 136926 & IGS & $1.24 \mathrm{E}-07$ \\
\hline 34 & $\mathrm{P}$ & 113576 & IGS & 136958 & IGS & $1.24 \mathrm{E}-07$ \\
\hline 43 & $\mathrm{P}$ & 122739 & IGS & 122739 & IGS & $3.13 \mathrm{E}-11$ \\
\hline 38 & $\mathrm{P}$ & 125999 & $n d h A$ intron & 146116 & IGS & $6.09 \mathrm{E}-10$ \\
\hline 35 & $\mathrm{P}$ & 126392 & $n d h A$ intron & 126392 & $n d h A$ intron & $1.09 \mathrm{E}-06$ \\
\hline 31 & $\mathrm{~F}$ & 130542 & $y c f 1$ & 130563 & $y c f 1$ & $6.60 \mathrm{E}-06$ \\
\hline 34 & $\mathrm{~F}$ & 136926 & IGS & 136958 & IGS & $1.24 \mathrm{E}-07$ \\
\hline 33 & $\mathrm{~F}$ & 153465 & $y c f 2$ & 153501 & $y c f 2$ & $1.45 \mathrm{E}-05$ \\
\hline 47 & $\mathrm{~F}$ & 153482 & $y c f 2$ & 153500 & $y c f 2$ & $1.61 \mathrm{E}-13$ \\
\hline 38 & $\mathrm{~F}$ & 153491 & $y c f 2$ & 153509 & $y c f 2$ & $6.09 \mathrm{E}-10$ \\
\hline 30 & $\mathrm{~F}$ & 153499 & $y c f 2$ & 153517 & $y c f 2$ & $5.68 \mathrm{E}-07$ \\
\hline 31 & $\mathrm{~F}$ & 155941 & $y c f 2$ & 155962 & $y c f 2$ & $1.47 \mathrm{E}-07$ \\
\hline \multicolumn{7}{|c|}{ 丹霞梧桐 Firmiana danxiaensis } \\
\hline 45 & $\mathrm{P}$ & 4372 & IGS & 4372 & IGS & $7.98 \mathrm{E}-16$ \\
\hline 30 & $\mathrm{P}$ & 8000 & $t R N A-G C U$ & 48084 & $\operatorname{trn} S-G G A$ & $5.71 \mathrm{E}-07$ \\
\hline 47 & $\mathrm{P}$ & 9796 & IGS & 9796 & IGS & $5.21 \mathrm{E}-17$ \\
\hline 30 & $\mathrm{P}$ & 10078 & IGS & 10078 & IGS & $2.48 \mathrm{E}-05$ \\
\hline 35 & $\mathrm{P}$ & 10189 & IGS & 10200 & IGS & $3.32 \mathrm{E}-08$ \\
\hline 39 & $\mathrm{~F}$ & 29987 & IGS & 30006 & IGS & $2.42 \mathrm{E}-14$ \\
\hline 30 & $\mathrm{R}$ & 38301 & IGS & 38301 & IGS & $6.34 \mathrm{E}-09$ \\
\hline 49 & $\mathrm{~F}$ & 40946 & psaB & 43170 & psaA & $2.44 \mathrm{E}-16$ \\
\hline 41 & $\mathrm{~F}$ & 40954 & $p s a B$ & 43178 & $p s a A$ & $1.86 \mathrm{E}-13$ \\
\hline 30 & $\mathrm{R}$ & 44185 & IGS & 44185 & IGS & $2.48 \mathrm{E}-05$ \\
\hline 32 & $\mathrm{P}$ & 44575 & IGS & 44575 & IGS & $1.77 \mathrm{E}-06$ \\
\hline 41 & $\mathrm{~F}$ & 46192 & $y c f 3$ intron & 126437 & $n d h A$ intron & $4.35 \mathrm{E}-10$ \\
\hline 36 & $\mathrm{~F}$ & 46197 & $y c f 3$ intron & 104749 & IGS & $1.67 \mathrm{E}-10$ \\
\hline 36 & $\mathrm{P}$ & 46197 & $y c f 3$ intron & 146610 & IGS & $1.67 \mathrm{E}-10$ \\
\hline 30 & $\mathrm{~F}$ & 46206 & $y c f 3$ intron & 104758 & IGS & $5.71 \mathrm{E}-07$ \\
\hline 30 & $\mathrm{P}$ & 46206 & $y c f 3$ intron & 146607 & IGS & $5.71 \mathrm{E}-07$ \\
\hline 31 & $\mathrm{~F}$ & 73203 & IGS & 73223 & IGS & $6.64 \mathrm{E}-06$ \\
\hline 34 & $\mathrm{R}$ & 77207 & clpP intron & 77207 & clpP intron & $1.25 \mathrm{E}-07$ \\
\hline 48 & $\mathrm{P}$ & 79882 & IGS & 79882 & IGS & $9.23 \mathrm{E}-20$ \\
\hline 30 & $\mathrm{~F}$ & 87921 & IGS & 87951 & IGS & $6.34 \mathrm{E}-09$ \\
\hline 31 & $\mathrm{~F}$ & 94910 & $y c f 2$ & 94931 & $y c f 2$ & $1.47 \mathrm{E}-07$ \\
\hline 31 & $\mathrm{P}$ & 94910 & $y c f 2$ & 156433 & $y c f 2$ & $1.47 \mathrm{E}-07$ \\
\hline 31 & $\mathrm{P}$ & 94931 & $y c f 2$ & 156454 & $y c f 2$ & $1.47 \mathrm{E}-07$ \\
\hline 47 & $\mathrm{~F}$ & 97356 & $y c f 2$ & 97374 & $y c f 2$ & $1.62 \mathrm{E}-13$ \\
\hline
\end{tabular}


陆奇丰, 黄至欢, 骆文华 (2021) 极小种群濒危植物广西火桐、丹霞梧桐的叶绿体基因组特征. 生物多样性, 29(5), 586-595. http://www.biodiversity-science.net/CN/10.17520/biods.2020263

\begin{tabular}{|c|c|c|c|c|c|c|}
\hline $\begin{array}{l}\text { 序列长度 } \\
\text { Length (bp) }\end{array}$ & $\begin{array}{l}\text { 重复类型 } \\
\text { Repeat type }\end{array}$ & $\begin{array}{l}\text { 重复 } 1 \text { 起始位点 } \\
\text { Repeat } 1 \text { start } \\
\text { position }\end{array}$ & $\begin{array}{l}\text { 重复 } 1 \text { 位置 } \\
\text { Repeat } 1 \\
\text { location }\end{array}$ & $\begin{array}{l}\text { 重复 } 2 \text { 起始位点 } \\
\text { Repeat } 2 \text { start } \\
\text { position }\end{array}$ & $\begin{array}{l}\text { 重复 } 2 \text { 位置 } \\
\text { Repeat } 2 \text { location }\end{array}$ & $\begin{array}{l}\mathrm{E} \text { 值 } \\
\text { E value }\end{array}$ \\
\hline \multicolumn{7}{|c|}{ 丹霞梧桐 Firmiana danxiaensis } \\
\hline 47 & $\mathrm{P}$ & 97356 & $y c f 2$ & 153974 & $y c f 2$ & $1.62 \mathrm{E}-13$ \\
\hline 35 & $\mathrm{~F}$ & 97368 & $y c f 2$ & 97386 & $y c f 2$ & $3.32 \mathrm{E}-08$ \\
\hline 35 & $\mathrm{P}$ & 97368 & $y c f 2$ & 153974 & $y c f 2$ & 3.32E-08 \\
\hline 33 & $\mathrm{~F}$ & 97369 & $y c f 2$ & 97405 & $y c f 2$ & $1.46 \mathrm{E}-05$ \\
\hline 33 & $\mathrm{P}$ & 97369 & $y c f 2$ & 153957 & $y c f 2$ & $1.46 \mathrm{E}-05$ \\
\hline 47 & $\mathrm{P}$ & 97374 & $y c f 2$ & 153992 & $y c f 2$ & $1.62 \mathrm{E}-13$ \\
\hline 35 & $\mathrm{P}$ & 97386 & $y c f 2$ & 153992 & $y c f 2$ & $3.32 \mathrm{E}-08$ \\
\hline 33 & $\mathrm{P}$ & 97405 & $y c f 2$ & 153993 & $y c f 2$ & $1.46 \mathrm{E}-05$ \\
\hline 38 & $\mathrm{~F}$ & 104749 & IGS & 126442 & $n d h A$ intron & $6.12 \mathrm{E}-10$ \\
\hline 34 & $\mathrm{~F}$ & 113911 & $r r n 4.5$ & 113943 & $r r n 4.5$ & $1.25 \mathrm{E}-07$ \\
\hline 34 & $\mathrm{P}$ & 113911 & $r r n 4.5$ & 137418 & $r r n 4.5$ & $1.25 \mathrm{E}-07$ \\
\hline 34 & $\mathrm{P}$ & 113943 & $r r n 4.5$ & 137450 & $r r n 4.5$ & $1.25 \mathrm{E}-07$ \\
\hline 33 & $\mathrm{R}$ & 115673 & IGS & 115673 & IGS & 4.71E-07 \\
\hline 60 & $\mathrm{~F}$ & 115688 & IGS & 115708 & IGS & $9.90 \mathrm{E}-25$ \\
\hline 40 & $\mathrm{~F}$ & 115688 & IGS & 115728 & IGS & $4.25 \mathrm{E}-11$ \\
\hline 30 & $\mathrm{R}$ & 115857 & IGS & 115858 & IGS & $5.71 \mathrm{E}-07$ \\
\hline 38 & $\mathrm{P}$ & 126442 & $n d h A$ intron & 146608 & IGS & $6.12 \mathrm{E}-10$ \\
\hline 34 & $\mathrm{P}$ & 126836 & $n d h A$ intron & 126836 & $n d h A$ intron & $1.25 \mathrm{E}-07$ \\
\hline 31 & $\mathrm{~F}$ & 134006 & $y c f 1$ & 134033 & $y c f 1$ & $6.64 \mathrm{E}-06$ \\
\hline 34 & $\mathrm{~F}$ & 137418 & $r r n 4.5$ & 137450 & $r r n 4.5$ & $1.25 \mathrm{E}-07$ \\
\hline 33 & $\mathrm{~F}$ & 153957 & $y c f 2$ & 153993 & $y c f 2$ & $1.46 \mathrm{E}-05$ \\
\hline 47 & $\mathrm{~F}$ & 153974 & $y c f 2$ & 153992 & $y c f 2$ & $1.62 \mathrm{E}-13$ \\
\hline 38 & $\mathrm{~F}$ & 153983 & $y c f 2$ & 154001 & $y c f 2$ & $6.12 \mathrm{E}-10$ \\
\hline 30 & $\mathrm{~F}$ & 153991 & $y c f 2$ & 154009 & $y c f 2$ & $5.71 \mathrm{E}-07$ \\
\hline 31 & $\mathrm{~F}$ & 156433 & $y c f 2$ & 156454 & $y c f 2$ & $1.47 \mathrm{E}-07$ \\
\hline
\end{tabular}


陆奇丰, 黄至欢, 骆文华 (2021) 极小种群濒危植物广西火桐、丹霞梧桐的叶绿体基因组特征. 生物多样性, 29(5), 586-595

http://www.biodiversity-science.net/CN/10.17520/biods.2020263

附录 4 广西火桐和丹霞梧桐的串联重复序列

Appendix 4 The tandem repeat sequences identified in Firmiana kwangsiensis and F.danxiaensis chloroplast genome

\begin{tabular}{|c|c|c|c|c|c|c|}
\hline 起始点 & 终止点 & 重复单 & 重复单 比对得分 & 重复单元序列 & 串联重复序列 & 串联重复序 \\
\hline \multirow[t]{4}{*}{ Start } & End & 元长度 & 元数量 Alignment & Sequence of the repeat unit & Sequence of the entire repeat & 列所在位置 \\
\hline & & Size of & Copy of score & & & Region \\
\hline & & repeat & Repeat & & & \\
\hline & & unit & Units & & & \\
\hline
\end{tabular}

广西火桐 Firmiana kwangsiensis

\begin{tabular}{|c|c|c|c|c|c|c|c|}
\hline 155 & 184 & 15 & 2.0 & 60 & TAAAGAAAAAACAAA & TAAAGAAAAAACAAATAAAGAAAAAACAAA & IGS \\
\hline 8305 & 8345 & 21 & 2.0 & 82 & TATAGATATATACAACTTTTC & TATAGATATATACAACTTTTCTATAGATATATACAACTTTT & IGS \\
\hline 28976 & 29003 & 14 & 2.0 & 56 & AGCAAAAACAAGTG & AGCAAAAACAAGTGAGCAAAAACAAGTG & IGS \\
\hline 38039 & 38065 & 13 & 2.1 & 54 & TAATTATTCTAAT & TAATTATTCTAАTTAАTТАТTCTAАTT & IGS \\
\hline 38757 & 38784 & 14 & 2.0 & 56 & ATAGTTGACTGTAA & ATAGTTGACTGTAAATAGTTGACTGTAA & IGS \\
\hline 44135 & 44165 & 15 & 2.1 & 62 & TATCTATCTATTTTT & TATCTATCTATTTTTTATCTATCTATTTTTT & IGS \\
\hline 44720 & 44755 & 18 & 2.0 & 72 & ATTAAATTAATATTTTTT & ATTAAATTAATATTTTTTATTAAATTAATATTTTTT & IGS \\
\hline 44806 & 44845 & 20 & 2.0 & 80 & TAAGGTAATTTATTTAATTA & TAAGGTAATTTATTTAATTATAAGGTAATTTATTTAATTA & IGS \\
\hline 49642 & 49668 & 12 & 2.3 & 54 & ATTCAATCTAAT & ATTCAАTCTAАTATTCAАTCTAАTATT & IGS \\
\hline 49672 & 49700 & 15 & 1.9 & 58 & AGAATATAATAATTA & AGAATATAATAATTAAGAATATAATAATTA & IGS \\
\hline 50030 & 50063 & 15 & 2.3 & 68 & AATAGAAATGAATGG & AATAGAAATGAATGGAATAGAAATGAATGGAATA & IGS \\
\hline \multirow[t]{2}{*}{54424} & 54475 & 26 & 2.0 & 104 & TCGATATAGTACTAATTTGTATA & TCGATATAGTACTAATTTGTATAGTATCGATATAGTACTAATTTGTATAGT & IGS \\
\hline & & & & & GTA & A & \\
\hline 63302 & 63334 & 16 & 2.1 & 66 & ААТTTТАТСТТССТСТ & ААТTTTАТСТTССТСТААТТTТАТСТTССТСТА & IGS \\
\hline \multirow[t]{2}{*}{63399} & 63461 & 32 & 2.0 & 126 & ATCTCCCGAGAATTCTATTTTGA & ATCTCCCGAGAATTCTATTTTGACTAAAAATCATCTCCCGAGAATTCTATT & IGS \\
\hline & & & & & CTAAAAATC & TTGACTAAAAAT & \\
\hline
\end{tabular}


陆奇丰, 黄至欢, 骆文华 (2021) 极小种群濒危植物广西火桐、丹霞梧桐的叶绿体基因组特征. 生物多样性, 29(5), 586-595. http://www.biodiversity-science.net/CN/10.17520/biods.2020263

\begin{tabular}{|c|c|c|c|c|c|c|c|}
\hline 起始点 & 终止点 & 重复单 & 重复单 & 比对得分 & 重复单元序列 & 串联重复序列 & 串联重复序 \\
\hline \multirow[t]{4}{*}{ Start } & \multirow[t]{4}{*}{ End } & 元长度 & 元数量 & \multirow{4}{*}{$\begin{array}{l}\text { Alignment } \\
\text { score }\end{array}$} & \multirow[t]{4}{*}{ Sequence of the repeat unit } & \multirow[t]{4}{*}{ Sequence of the entire repeat } & 列所在位置 \\
\hline & & Size of & Copy of & & & & Region \\
\hline & & repeat & Repeat & & & & \\
\hline & & unit & Units & & & & \\
\hline \multicolumn{8}{|c|}{ 广西火桐 Firmiana kwangsiensis } \\
\hline 63733 & 63766 & 17 & 2.0 & 68 & TTAGATATACTTAGTAT & TTAGATATACTTAGTATTTAGATATACTTAGTAT & IGS \\
\hline 68340 & 68378 & 18 & 2.2 & 78 & TATTAAGTATAAAATAAG & TATTAAGTATAAAATAAGTATTAAGTATAAAATAAGTAT & IGS \\
\hline 76830 & 76867 & 17 & 2.2 & 76 & ATTTATATATATTTATA & ATTTATATATATTTATAATTTATATATATTTATAATTT & $C l p P$ intron \\
\hline 90443 & 90473 & 14 & 2.2 & 62 & TATCGTATAATTCT & TATCGTATAATTCTTATCGTATAATTCTTAT & $r p l 2$ intron \\
\hline 105310 & 105337 & 14 & 2.0 & 56 & TTTTCTATTCTATT & TTTTCTATTCTATTTTTTCTATTCTATT & IGS \\
\hline 145200 & 145227 & 14 & 2.0 & 56 & AATAGAATAGAAAA & AATAGAATAGAAAAAATAGAATAGAAAA & IGS \\
\hline 160064 & 160094 & 14 & 2.2 & 62 & ATAAGAATTATACG & ATAAGAATTATACGATAAGAATTATACGATA & rpl2 intron \\
\hline \multicolumn{8}{|c|}{ 丹霞梧桐 Firmiana danxiaensis } \\
\hline 155 & 184 & 15 & 2.0 & 60 & TAAAGAAAAAACAAA & TAAAGAAAAAACAAATAAAGAAAAAACAAA & IGS \\
\hline 6494 & 6530 & 19 & 1.9 & 74 & СТTТTCTATTCTAАTTAAG & СТTTTCTATTCTAATTAAGCTTTTCTATTCTAATTAA & IGS \\
\hline 9781 & 9813 & 16 & 2.1 & 66 & TAATTCAATTCAATGA & TAATTCAATTCAATGATAATTCAATTCAATGAT & IGS \\
\hline 10141 & 10165 & 12 & 2.1 & 50 & TAATTAGATAAT & TAATTAGATAATTAATTAGATAATT & IGS \\
\hline \multirow[t]{2}{*}{29988} & 30045 & 19 & 3.1 & 116 & ACTGTTCAAAGAGAAAAAA & ACTGTTCAAAGAGAAAAAAACTGTTCAAAGAGAAAAAAACTGTTCAAAG & IGS \\
\hline & & & & & & AGAAAAAAA & \\
\hline 38112 & 38138 & 13 & 2.1 & 54 & TAATTATTCTAAT & TAATTATTCTAАTTAАTTATTCTAАТ T & IGS \\
\hline 38248 & 38274 & 13 & 2.1 & 54 & ATATTAGAATATT & ATATTAGAATATTATATTAGAATATT A & IGS \\
\hline 38271 & 38306 & 17 & 2.1 & 72 & ATTAGAATAATAATATA & ATTAGAATAATAATATAATTAGAATAATAATATAAT & IGS \\
\hline 44188 & 44218 & 15 & 2.1 & 62 & TATCTATCTATTTTT & TATCTATCTATTTTTTATCTATCTATTTTTT & IGS \\
\hline
\end{tabular}


陆奇丰, 黄至欢, 骆文华 (2021) 极小种群濒危植物广西火桐、丹霞梧桐的叶绿体基因组特征. 生物多样性, 29(5), 586-595. http://www.biodiversity-science.net/CN/10.17520/biods.2020263

\begin{tabular}{|c|c|c|c|c|c|c|c|}
\hline 起始点 & 终止点 & 重复单 & 重复单 & 比对得分 & 重复单元序列 & 串联重复序列 & 串联重复序 \\
\hline \multirow[t]{4}{*}{ Start } & End & 元长度 & 元数量 & Alignment & Sequence of the repeat unit & Sequence of the entire repeat & 列所在位置 \\
\hline & & Size of & Copy of & score & & & Region \\
\hline & & repeat & Repeat & & & & \\
\hline & & unit & Units & & & & \\
\hline \multicolumn{8}{|c|}{ 丹霞梧桐 Firmiana danxiaensis } \\
\hline 44776 & 44813 & 18 & 2.1 & 76 & ATTAAАTTAАТАТTTTTT & ATTAAATTAATATTTTTTATTAAATTAATATTTTTTAT & IGS \\
\hline 44855 & 44894 & 20 & 2.0 & 80 & TAAGGTAATTTATTTAATTA & TAAGGTAATTTATTTAATTATAAGGTAATTTATTTAATTA & IGS \\
\hline 49665 & 49702 & 18 & 2.1 & 76 & TACTTAATATAACATATT & TACTTAATATAACATATTTACTTAATATAACATATTTA & IGS \\
\hline 49869 & 49894 & 13 & 2.0 & 52 & TTAGATTTAAATC & TTAGATTTAAATCTTAGATTTAAATC & IGS \\
\hline 50491 & 50524 & 15 & 2.3 & 68 & AATAGAAATGAATGG & AATAGAAATGAATGGAATAGAAATGAATGGAATA & IGS \\
\hline 50673 & 50714 & 20 & 2.1 & 84 & AATAAAAATGAAATTAAAGA & AATAAAAATGAAATTAAAGAAATAAAAATGAAATTAAAGAAA & IGS \\
\hline 55132 & 55160 & 13 & 2.2 & 58 & TATTTTATATCGA & TATTTTATATCGATATTTTATATCGATAT & IGS \\
\hline 55184 & 55223 & 20 & 2.0 & 80 & ATGTTATTTCTATATATTTA & ATGTTATTTCTATATATTTAATGTTATTTCTATATATTTA & IGS \\
\hline 63776 & 63808 & 16 & 2.1 & 66 & ААТTTТАТСТТССТСТ & ААТTTТАТСТТССТСТААТТТТАТСТТССТСТ А & IGS \\
\hline 64164 & 64197 & 17 & 2.0 & 68 & TTAGATATACTTAGTAT & TTAGATATACTTAGTATTTAGATATACTTAGTAT & IGS \\
\hline 68777 & 68815 & 18 & 2.2 & 78 & TATTAAGTATAAAATAAG & TATTAAGTATAAAATAAGTATTAAGTATAAAATAAGTAT & IGS \\
\hline 77209 & 77246 & 17 & 2.2 & 76 & ATTTATATATATTTATA & ATTTATATATATTTATAATTTATATATATTTATAATTT & $C l p P$ intron \\
\hline 83587 & 83618 & 15 & 2.1 & 64 & AAATGAAATAAATCC & AAATGAAATAAATCCAAATGAAATAAATCCAA & IGS \\
\hline \multirow[t]{2}{*}{87922} & 87981 & 30 & 2.0 & 120 & CTTAATTTAATATTTATTTAATA & CTTAATTTAATATTTATTTAATAATTTAATCTTAATTTAATATTTATTTAAT & IGS \\
\hline & & & & & ATTTAAT & AATTTAAT & \\
\hline 89825 & 89866 & 21 & 2.0 & 84 & TCTTTATTATATTAATATTAA & TCTTTATTATATTAATATTAATCTTTATTATATTAATATTAA & IGS \\
\hline 90810 & 90840 & 14 & 2.2 & 62 & TATCGTATAATTCT & TATCGTATAATTCTTATCGTATAATTCTTAT & $r p l 2$ intron \\
\hline 105678 & 105705 & 14 & 2.0 & 56 & TTTTCTATTCTATT & TTTTСТАТТСТАТТTТТTСТАТТСТАТТ & IGS \\
\hline
\end{tabular}


陆奇丰, 黄至欢, 骆文华 (2021) 极小种群濒危植物广西火桐、丹霞梧桐的叶绿体基因组特征. 生物多样性, 29(5), 586-595.

http://www.biodiversity-science.net/CN/10.17520/biods.2020263

\begin{tabular}{|c|c|c|c|c|c|c|c|}
\hline 起始点 & 终止点 & 重复单 & 重复单 & 比对得分 & 重复单元序列 & 串联重复序列 & 串联重复序 \\
\hline \multirow[t]{4}{*}{ Start } & End & 元长度 & 元数量 & Alignment & Sequence of the repeat unit & Sequence of the entire repeat & 列所在位置 \\
\hline & & Size of & Copy of & score & & & Region \\
\hline & & repeat & Repeat & & & & \\
\hline & & unit & Units & & & & \\
\hline
\end{tabular}

\section{丹霞梧桐 Firmiana danxiaensis}

$118358-118399-21$

AATATTATCAATTATTATTTA AATATTATCAATTATTATTTAAATATTATCAATTATTATTTA 